\title{
Má oclusão de Classe I de Angle, com tendência à classe III esquelética, tratada com controle de crescimento*
}

\author{
Ademir Roberto Brunetto**
}

\begin{abstract}
Resumo
A má oclusão de Classe III de Angle é caracterizada por uma relação dentária anteroposterior inadequada, que pode ou não estar acompanhada de alterações esqueléticas. Em geral, o aspecto facial fica bastante comprometido, principalmente quando associada à deficiência no terço médio da face, sendo esse, na maioria das vezes, o principal fator que motiva o paciente a procurar tratamento. Este caso foi apresentado à Diretoria do Board Brasileiro de Ortodontia e Ortopedia Facial (BBO), representando a categoria livre, como parte dos requisitos para a obtenção do título de Diplomado pelo BBO.
\end{abstract}

Palavras-chave: Má oclusão Classe III de Angle. Tração maxilar. Disjunção maxilar.

\section{HISTÓRIA E ETIOLOGIA}

Paciente de cor branca, gênero feminino, apresentou-se para exame inicial aos oito anos e quatro meses de idade, com bom estado geral de saúde. Sua história médica e odontológica se apresentava dentro dos padrões de normalidade, sem relato de doenças ou traumas. Sua queixa principal era o cruzamento do dente 21 (Fig. 1). Apresentava histórico familiar materno de padrão esquelético de classe III.

\section{DIAGNÓSTICO}

No aspecto dentário, a paciente, em fase de dentadura mista, era portadora de má oclusão de Classe I de Angle, com maxila atrésica, resultando, no aspecto transverso, num relacionamento topo a topo entre os arcos dentários. Na figura 1 pode-se observar uma maior expressão dessa atresia maxilar na área de caninos, e o cruzamento da unidade 21 (Fig. 1, 2). Vale ressaltar que, em manipulação mandibular, não houve variação da posição de relação cêntrica para a de oclusão cêntrica. Apresentava face simétrica com um perfil levemente convexo, selamento labial passivo e pouca exposição dos incisivos superiores no sorriso. $\mathrm{Na}$ análise da radiografia panorâmica, constatou-se presença de todos os dentes permanentes, com exceção dos terceiros molares. Notou-se, ainda, diminuição dos espaços para irrupção dos dentes 12 e 42, e presença de restaurações metálicas nos molares decíduos (Fig. 3).

Analisando cefalometricamente o relaciona- 

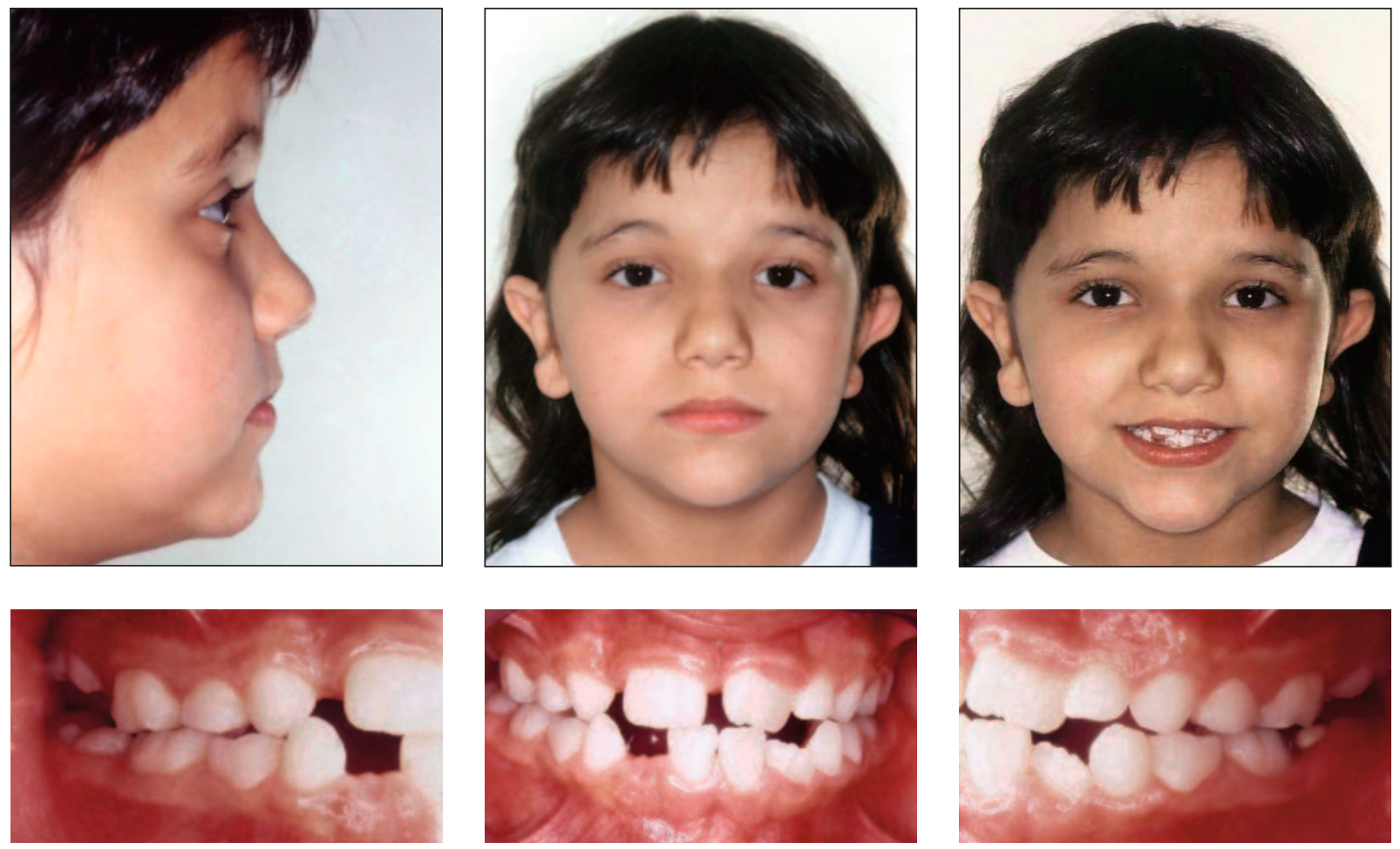

FIGURA 1 - Fotografias faciais e intrabucais iniciais.
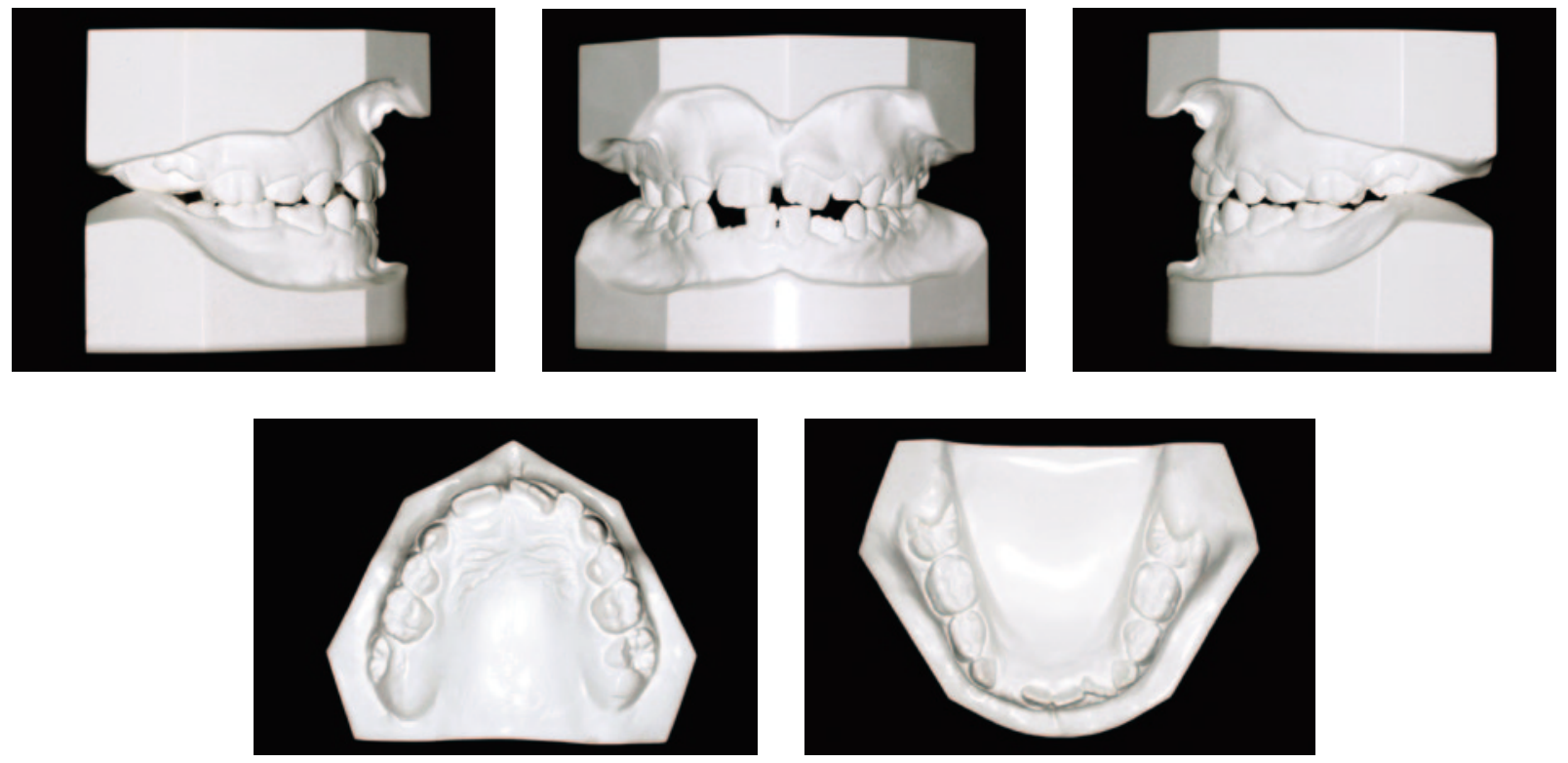

FIGURA 2 - Modelos iniciais

mento dos ossos maxilar e mandibular (SNA $=80^{\circ} \mathrm{e}$ $\mathrm{SNB}=7^{\circ}$ ), identificou-se discreta retrusão maxilar, considerando-se o ângulo $\mathrm{ANB}$, de $1^{\circ}$, reduzido para a faixa etária da paciente. $\mathrm{O}$ ângulo SN-GoGn de $30^{\circ}$ demonstrou um possível padrão de crescimento mandibular normal, tanto no sentido horizontal como no vertical (Fig. 4, Tab. 1). Contudo, havia o histórico familiar materno de padrão esquelético 


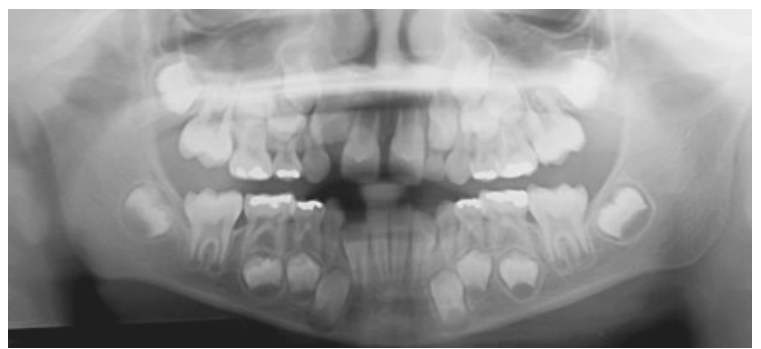

FIGURA 3 - Radiografia panorâmica inicial.
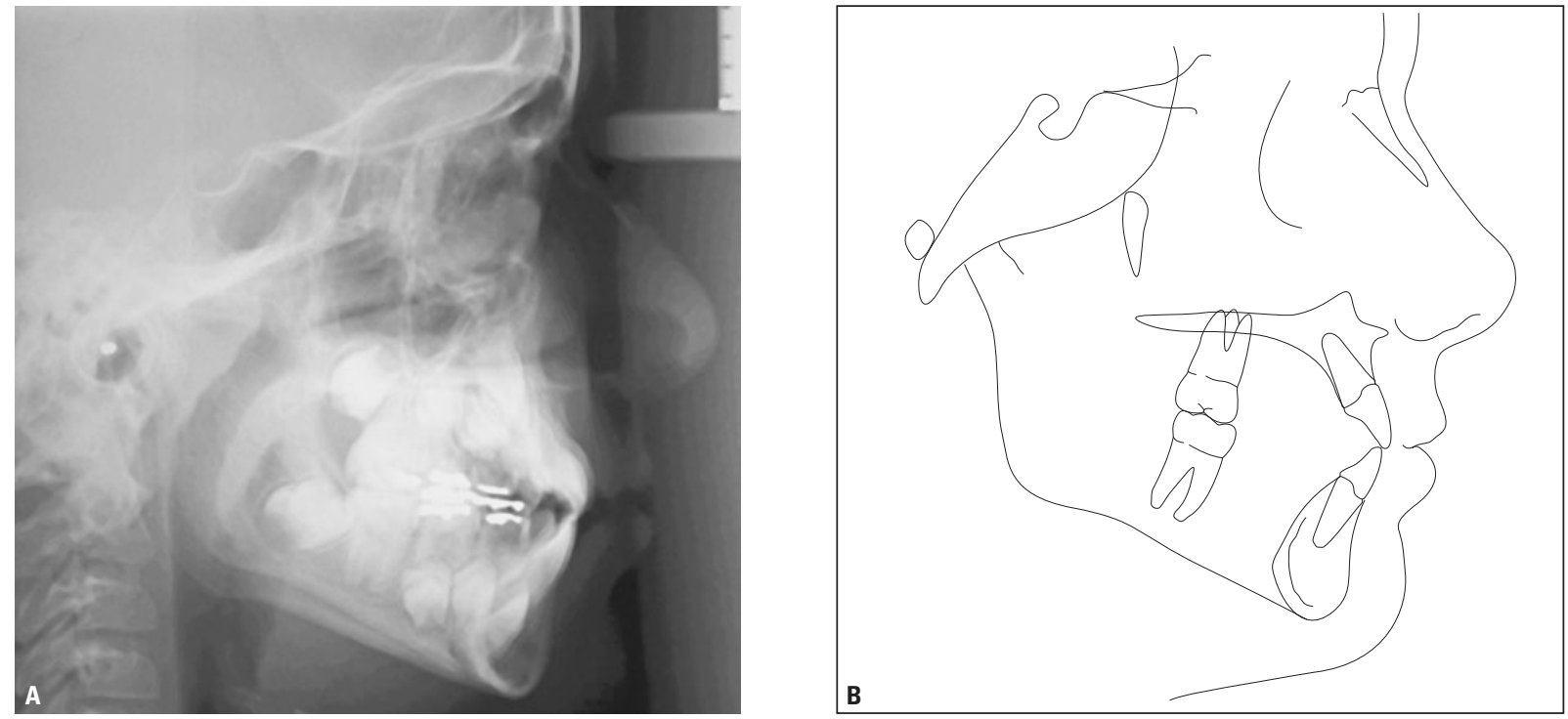

FIGURA 4 - Radiografia cefalométrica de perfil (A) e traçado cefalométrico (B) iniciais.

de classe III. Quanto ao aspecto dentário, apresentava incisivos superiores e inferiores levemente inclinados para vestibular $\left(1-\mathrm{NA}=25^{\circ}, 1-\mathrm{NB}=29^{\circ}\right.$ e IMPA $\left.=96^{\circ}\right)($ Tab. 1$)$.

\section{OBJETIVOS DO TRATAMENTO}

Nesta etapa, pretendeu-se obter o descruzamento do dente 21 e promover o aumento da maxila, no sentido transverso, permitindo a melhora do posicionamento dos dentes 53 e 63 e o aumento do espaço para irrupção do dente 12 , e realizar o tracionamento posteroanterior da maxila, com aumento do ângulo SNA e rotação da mandíbula no sentido horário, procurando-se estabelecer uma relação molar de Classe II. Com isso, esperava-se compensar o maior crescimento mandibular aguardado, pela tendência a um padrão esquelético de classe III.

Em relação ao aspecto facial, objetivou-se a melhora do perfil, com o deslocamento anterior do terço médio da face.

\section{PLANO DE TRATAMENTO ( $1^{\text {a }}$ FASE)}

Na primeira fase do tratamento, planejou-se a utilização do disjuntor de Haas modificado, apoiado nos segundos molares decíduos e associado à protração maxilar com máscara facial. Concomitantemente, seria recomendada a realização de exercícios com espátula de madeira (abaixador de língua), para o descruzamento do dente 21. Após isso, a paciente seria monitorada até o momento ideal para a execução da segunda fase do tratamento. 


\section{Progresso do tratamento}

$\mathrm{O}$ aparelho de Haas foi instalado, com ativações de $1 / 4$ de volta por dia, durante 18 dias. Associado a isso, a paciente utilizou o abaixador de língua, executando os exercícios três vezes ao dia, durante 15 dias, para o descruzamento do dente 21 .

Somente após a estabilização do disjuntor, a paciente passou a fazer uso da máscara facial. Inicialmente, aplicando uma força de $300 \mathrm{~g}$ em cada lado, passando, na sequência, para $500 \mathrm{~g}$, com uso mínimo de 14 horas por dia, durante 16 meses. Decorrido esse período, novos exames foram solicitados para avaliação das modificações ocorridas.

\section{Resultados obtidos}

Após a análise desses exames, observou-se que os objetivos propostos para a primeira fase haviam sido atingidos (Fig. 5 - 8). Houve aumento do ângulo ANB para $4^{\circ}$, com SNA $=85^{\circ}$ e $\mathrm{SNB}=81^{\circ}$, e o descruzamento do dente 21 , com melhor alinhamento na região anterossuperior. $\mathrm{O}$ perfil da paciente se tornou mais convexo, pelo deslocamento anterior do terço médio da face, tendo-se obtido aumento no valor do ângulo SNA para $85^{\circ}$ (Fig. 5, Tab. 1). Além disso, houve expressão de crescimento mandibular para frente e para baixo (Fig. 9A), com aumento do ângulo SNB para $81^{\circ}$ e manutenção do Eixo Y em $59^{\circ}$ (Tab. 1).

No aspecto dentário, os molares e incisivos superiores foram movimentados para distal e extruídos, além da obtenção de leve relação de Classe II nos caninos, pelo deslocamento anterior da maxila para frente e para baixo e consequente rotação da mandíbula no sentido horário (Fig. 9).

Passou-se, então, a acompanhar o desenvolvimento da paciente, com visitas ao consultório a cada seis meses, aguardando o momento de se iniciar a segunda fase do tratamento. Após 27 meses, observou-se, clinicamente, um relacionamento de chave de oclusão nos molares e de Classe III nos caninos. Além disso, os incisivos laterais superiores estavam cruzados e os incisivos centrais em topo com o arco antagonista (Fig. 10). Na oportunidade, foram solicitados novos exames para avaliação e planejamento da segunda fase de tratamento (Fig. 10 - 13).

Após a análise desses exames, verificou-se que o ângulo SNA era de $85^{\circ}$, ou seja, manteve-se exatamente igual. Contudo, o ângulo SNB havia passado para $83,5^{\circ}$, o que indicava um crescimento mandibular maior no sentido anterior, provocando a diminuição do ângulo ANB para 1,5 (Fig. 14, Tab. 1). $\mathrm{Na}$ avaliação dentária, a paciente apresentava uma relação de chave de oclusão nos molares e de Classe III nos caninos, com cruzamento anterior dos dentes 12 e 22 e permanência dos segundos molares decíduos inferiores (Fig. 10, 11).

\section{PLANO DE TRATAMENTO ( $2^{\text {a }}$ FASE)}

Devido a essa condição, optou-se pela utilização de nova tração maxilar com máscara facial, associada à disjunção palatina, pois a paciente ainda apresentava características físicas pré-puberais, na idade de 13 anos e 6 meses.

\section{Progresso do tratamento}

Fez-se nova disjunção palatina, com ativação de $1 / 4$ de volta por dia, durante uma semana, com o objetivo de romper a sutura palatina mediana. Em seguida, iniciou-se a tração com máscara facial, empregando-se $300 \mathrm{~g}$ de força por lado, aumentandose para 500g, durante 14 meses. Em seguida, novos exames foram solicitados para avaliação das modificações ocorridas (Fig. 15, 16).

\section{Resultados obtidos}

Com a aplicação da mecânica proposta, pode-se observar que os objetivos foram alcançados. Clinicamente, houve melhora no relacionamento anteroposterior dos arcos dentários (Fig. 15). Por meio da radiografia cefalométrica de perfil, observa-se o avanço anterior da maxila, em $2^{\circ}\left(\mathrm{SNA}=87^{\circ}\right)$, enquanto a mandíbula continuou seu crescimento para anterior $\left(\mathrm{SNB}=84^{\circ}\right)$, tendo o ângulo ANB aumentado para $3^{\circ}$ (Tab. 1). Quanto ao aspecto dentário, os molares e incisivos superiores foram mesialisados e extruídos. Obteve-se leve relação 

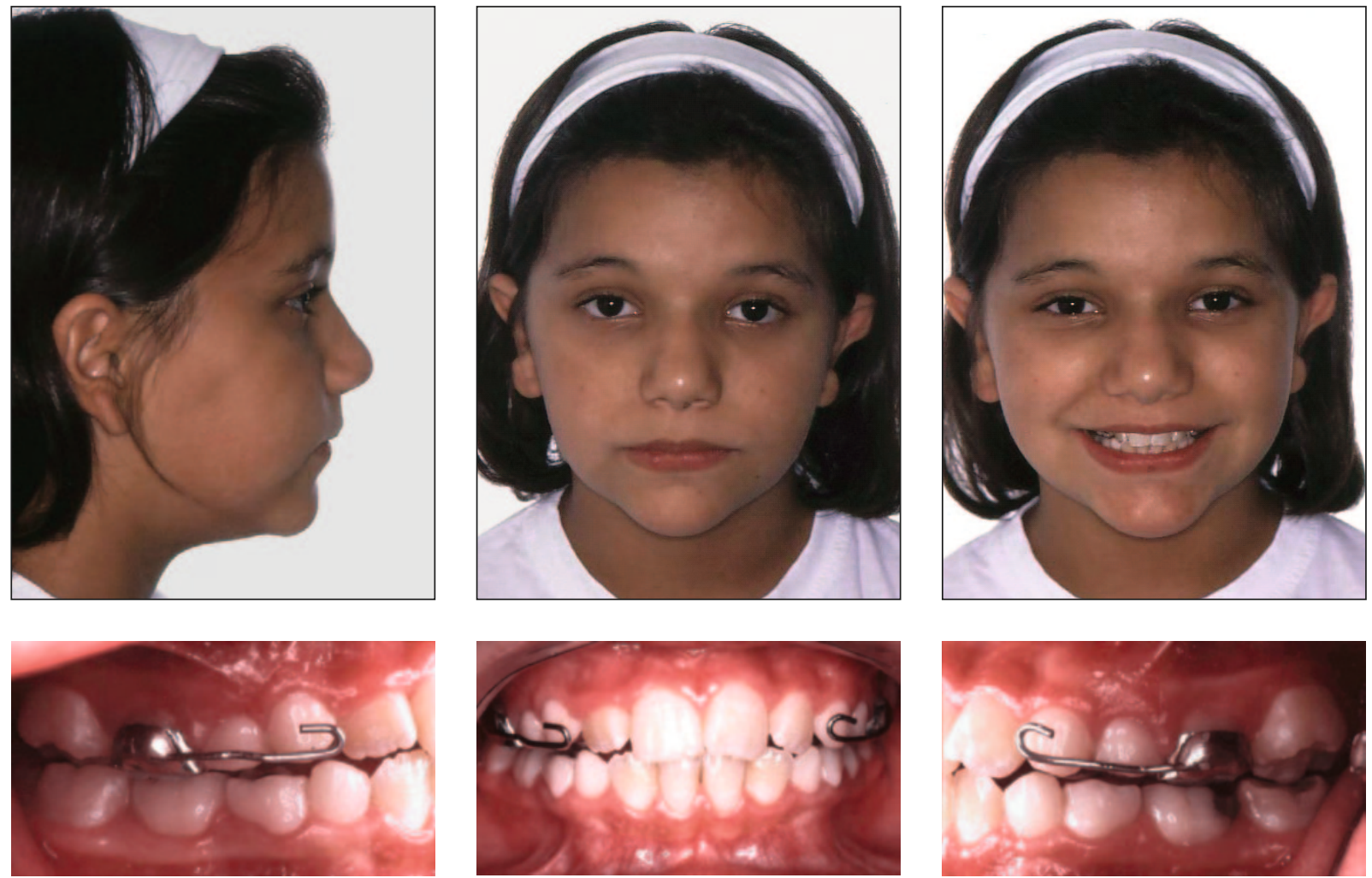

FIGURA 5 - Fotografias faciais e intrabucais intermediárias (A1).
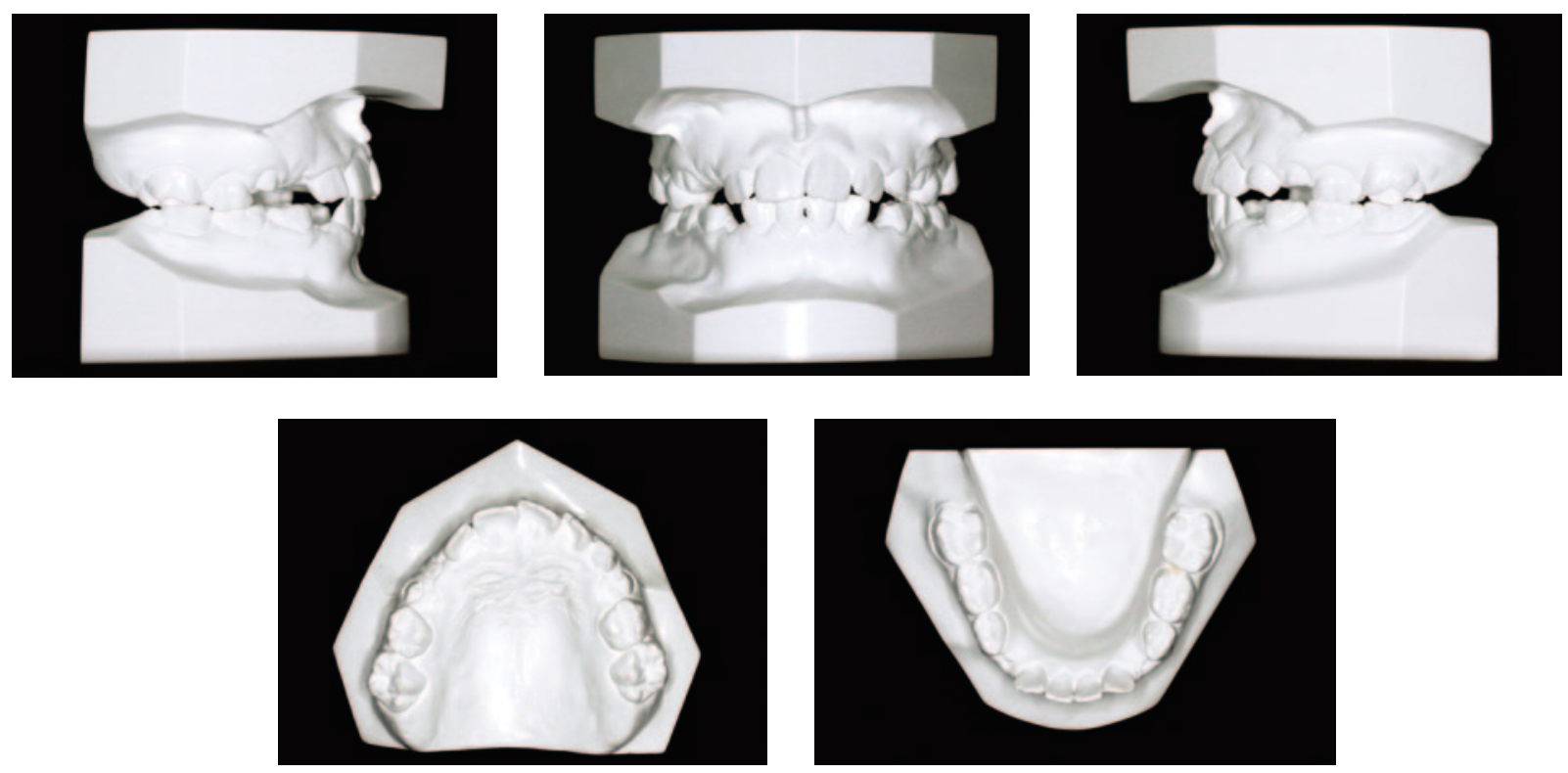

FIGURA 6 - Modelos intermediários (A1). 


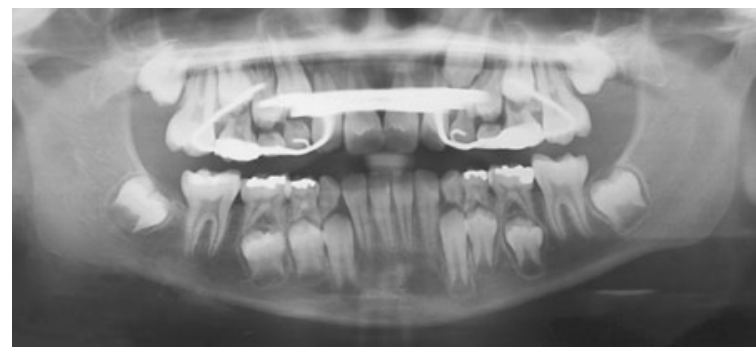

FIGURA 7 - Radiografia panorâmica intermediária (A1).
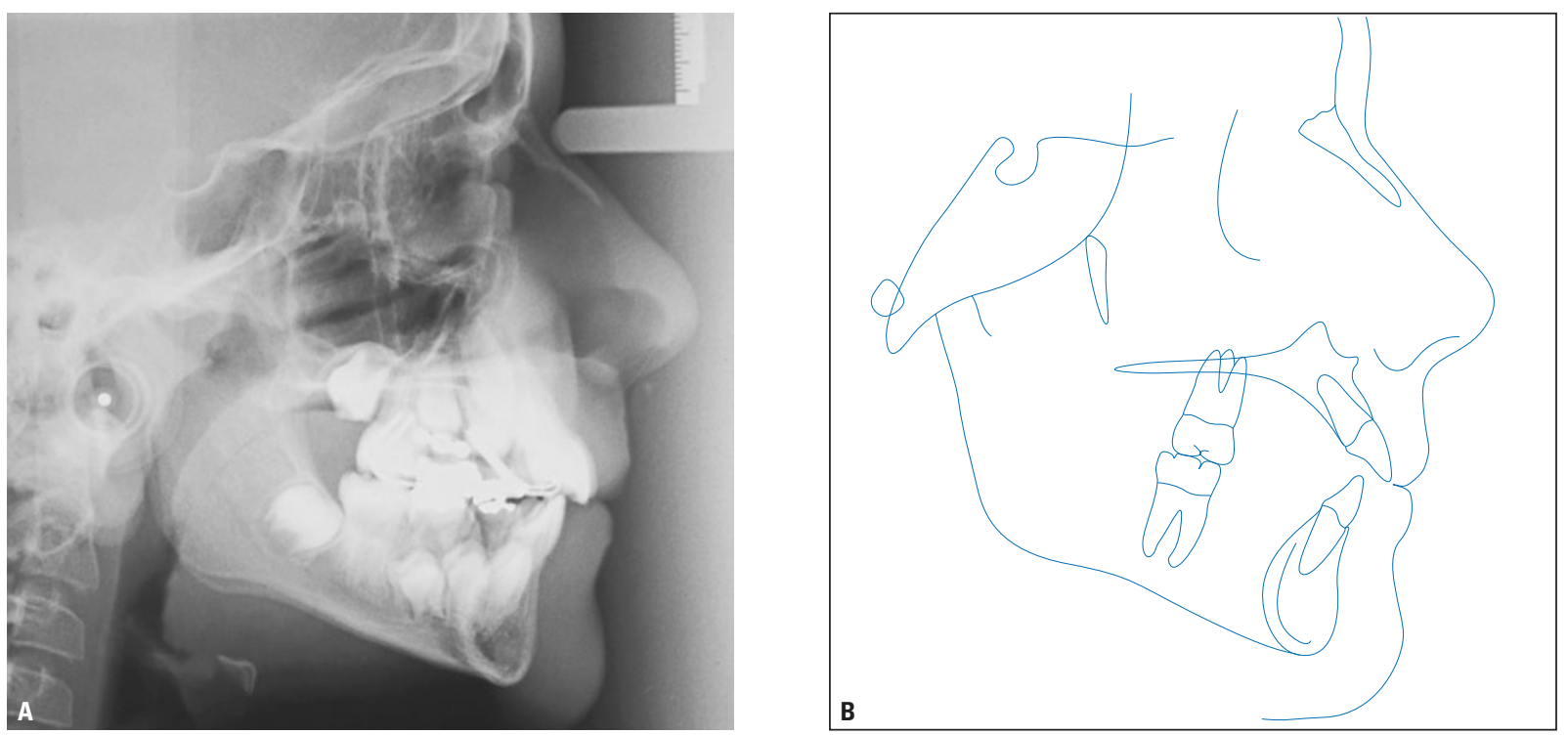

FIGURA 8 - Radiografia cefalométrica de perfil (A) e traçado cefalométrico (B) intermediários, após a primeira fase do tratamento (A1).
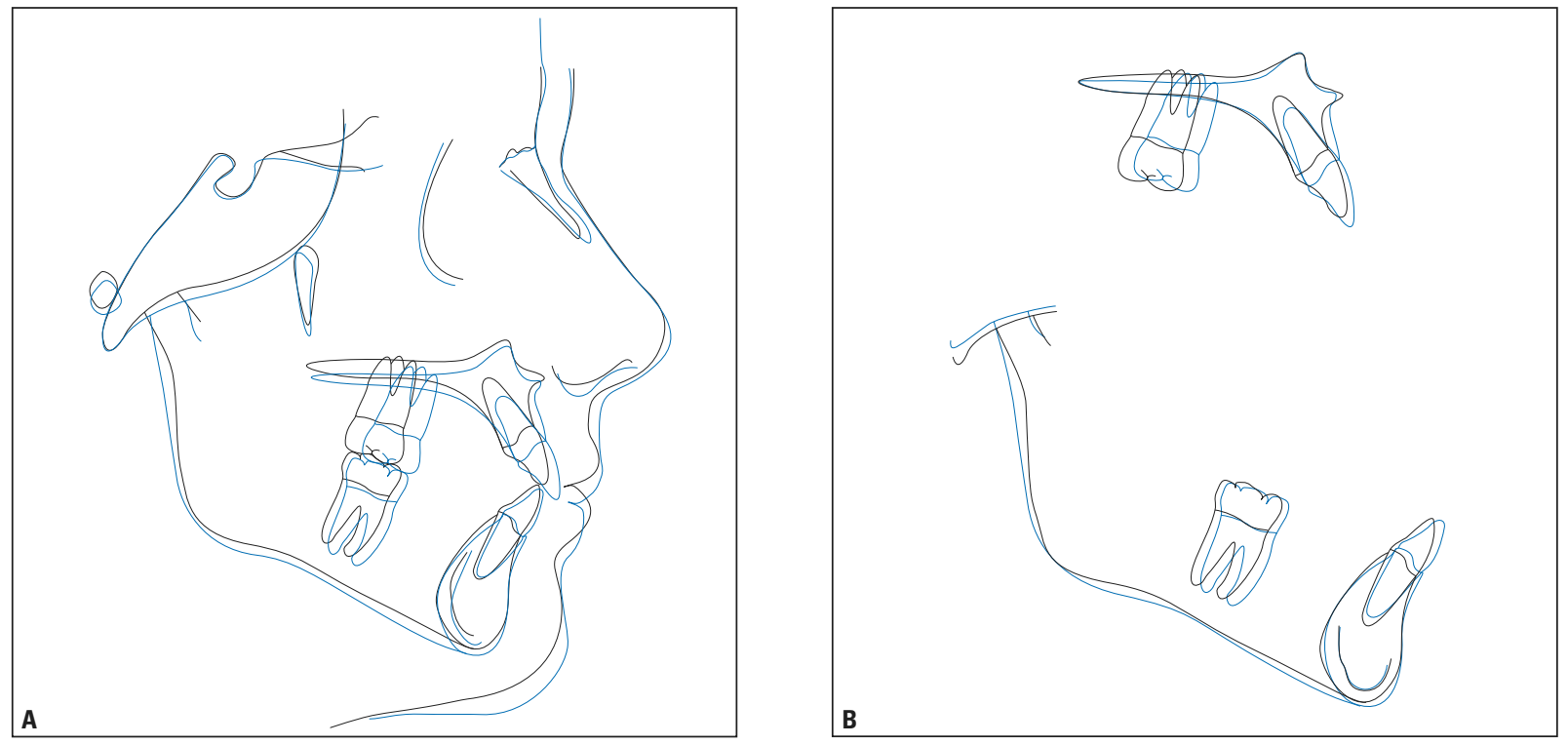

FIGURA 9 - Sobreposições total (A) e parciais (B) dos traçados cefalométricos inicial (preto) e intermediário A1 (azul). 

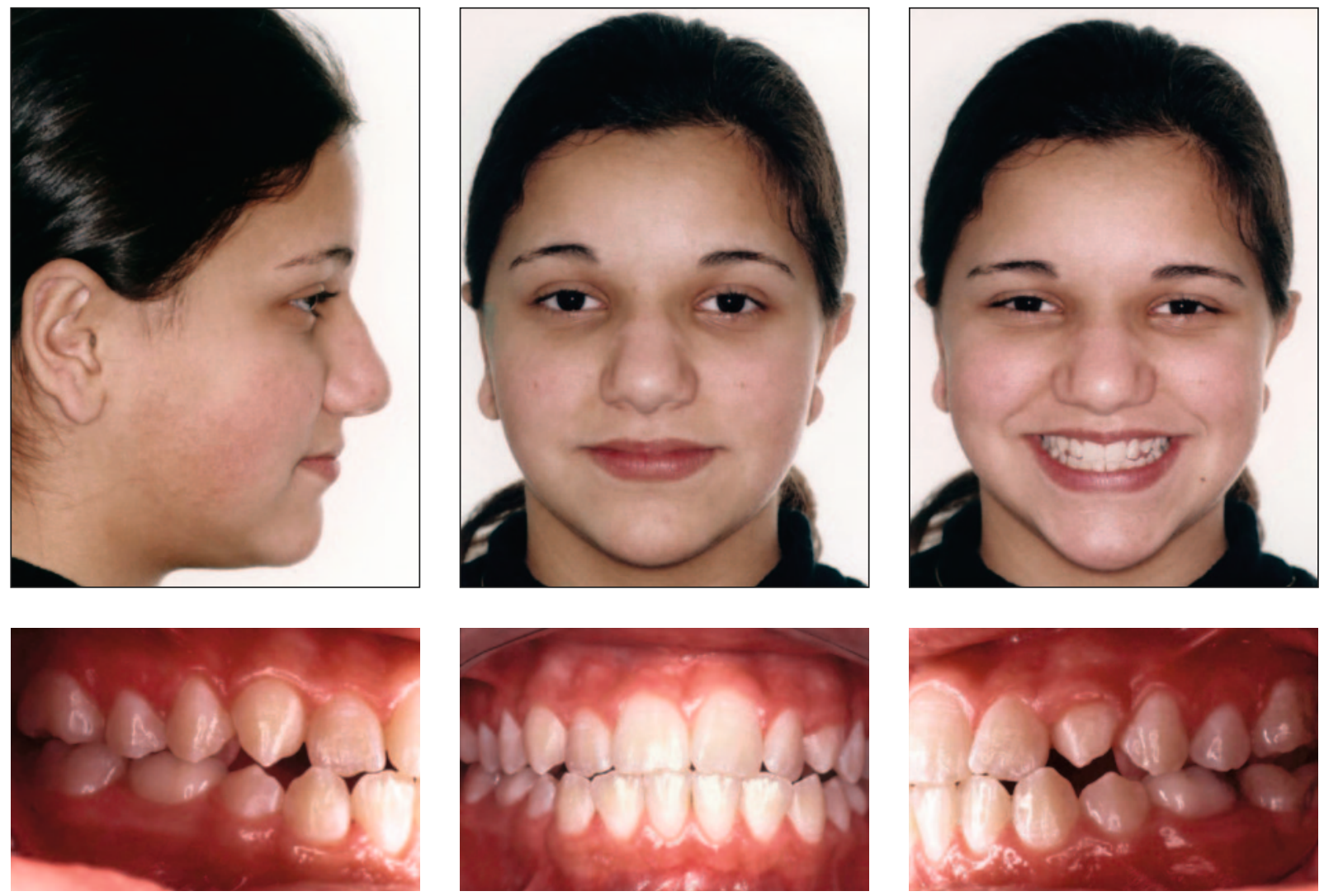

FIGURA 10 - Fotografias faciais e intrabucais intermediárias (A2).
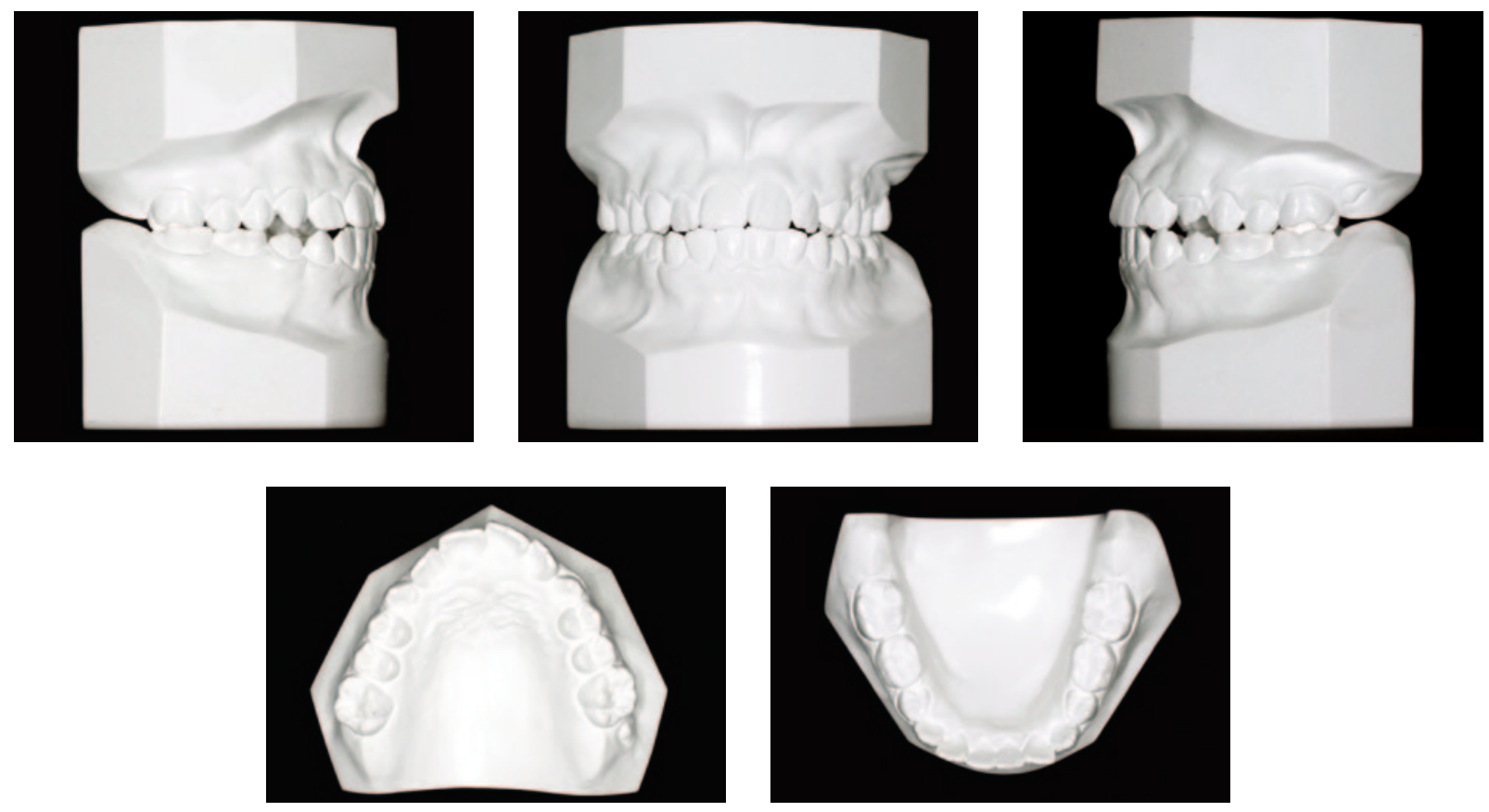

FIGURA 11 - Modelos intermediários (A2). 


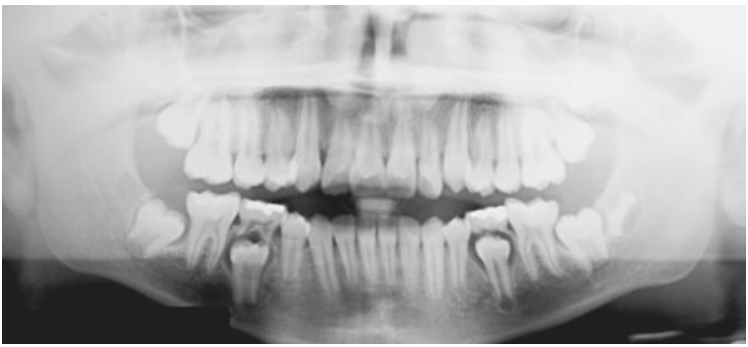

FIGURA 12 - Radiografia panorâmica intermediária (A2).
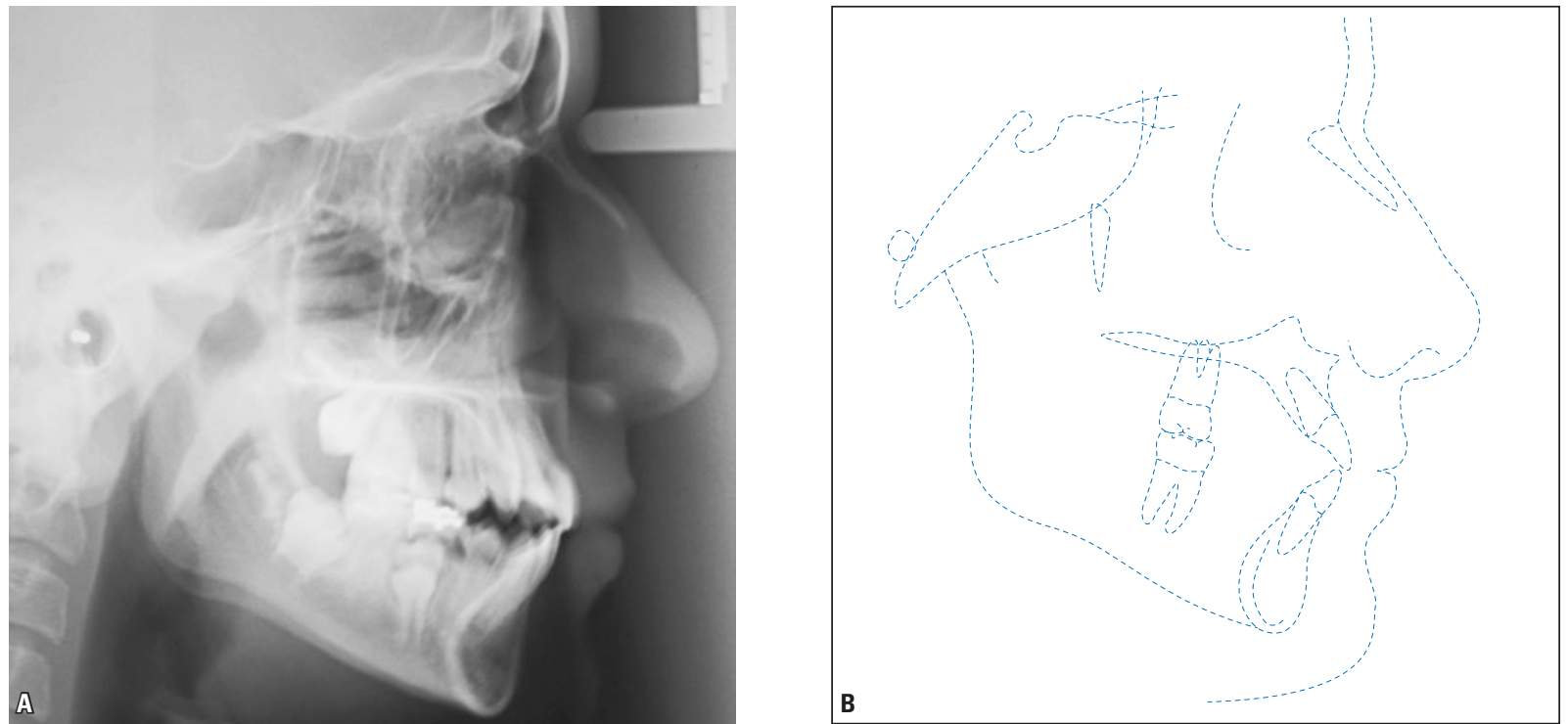

FIGURA 13 - Radiografia cefalométrica de perfil (A) e traçado cefalométrico (B) intermediários (A2), antes da segunda fase do tratamento.
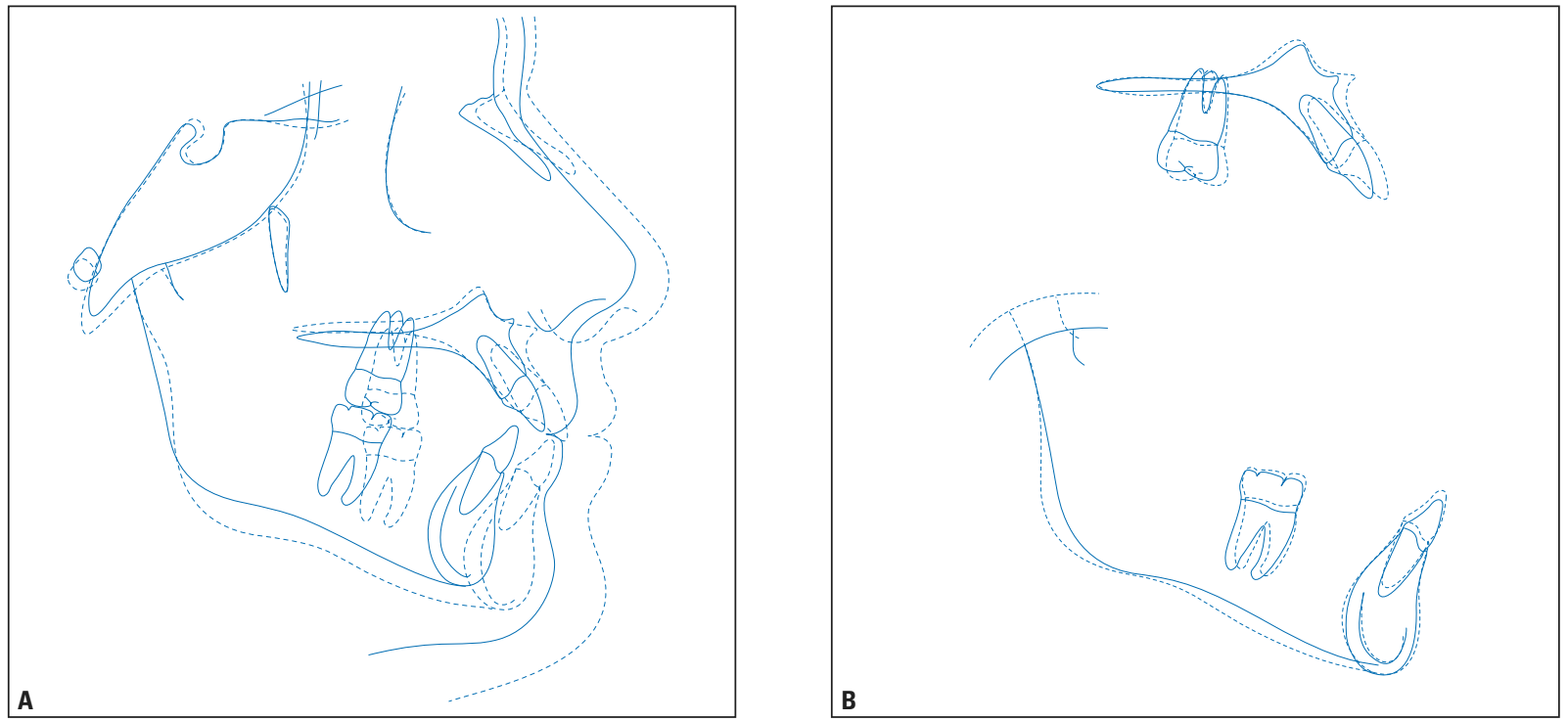

FIGURA 14 - Sobreposições total (A) e parciais (B) dos traçados cefalométricos intermediários A1 (azul) e intermediário A2 (azul tracejado). 
de Classe II na região dos caninos, auxiliada pelo deslocamento da maxila para frente e para baixo e consequente rotação da mandíbula no sentido horário (Fig. 16, 17).

\section{PLANO DE TRATAMENTO (3 ${ }^{\text {a }}$ FASE)}

A terceira fase do tratamento foi iniciada após a paciente ter passado pelo surto de crescimento puberal. Os objetivos foram o alinhamento dentário e a finalização do tratamento. Provavelmente, haveria necessidade de remoção dos terceiros molares.

Planejou-se a instalação de aparelho ortodôntico fixo Edgewise, com slot 0,018”, nos arcos dentários superior e inferior. Para a finalização, seriam utilizados arcos retangulares 0,016 ” x 0,022" de aço inoxidável, com dobras de primeira e terceira ordens, individualizadas de acordo com a necessidade, e elásticos intermaxilares. Após a finalização, seria iniciada a fase de contenção.

\section{Progresso do tratamento}

Iniciou-se a montagem da aparatologia fixa em ambos os arcos, com a colagem de braquetes metálicos standard, sem torques ou angulações. Foi utilizado o sistema Edgewise somente até os primeiros molares, devido aos segundos molares não estarem totalmente irrompidos.

De maneira sequencial, foram instalados arcos twist flex 0,014", seguidos de arcos 0,014" e 0,016" de aço inoxidável, com dobras de primeira ordem, para alinhamento e nivelamento. Posteriormente, foram instalados arcos de finalização 0,016 " x 0,022" de aço inoxidável, com dobras de primeira e terceira ordens individualizadas e uso de elástico
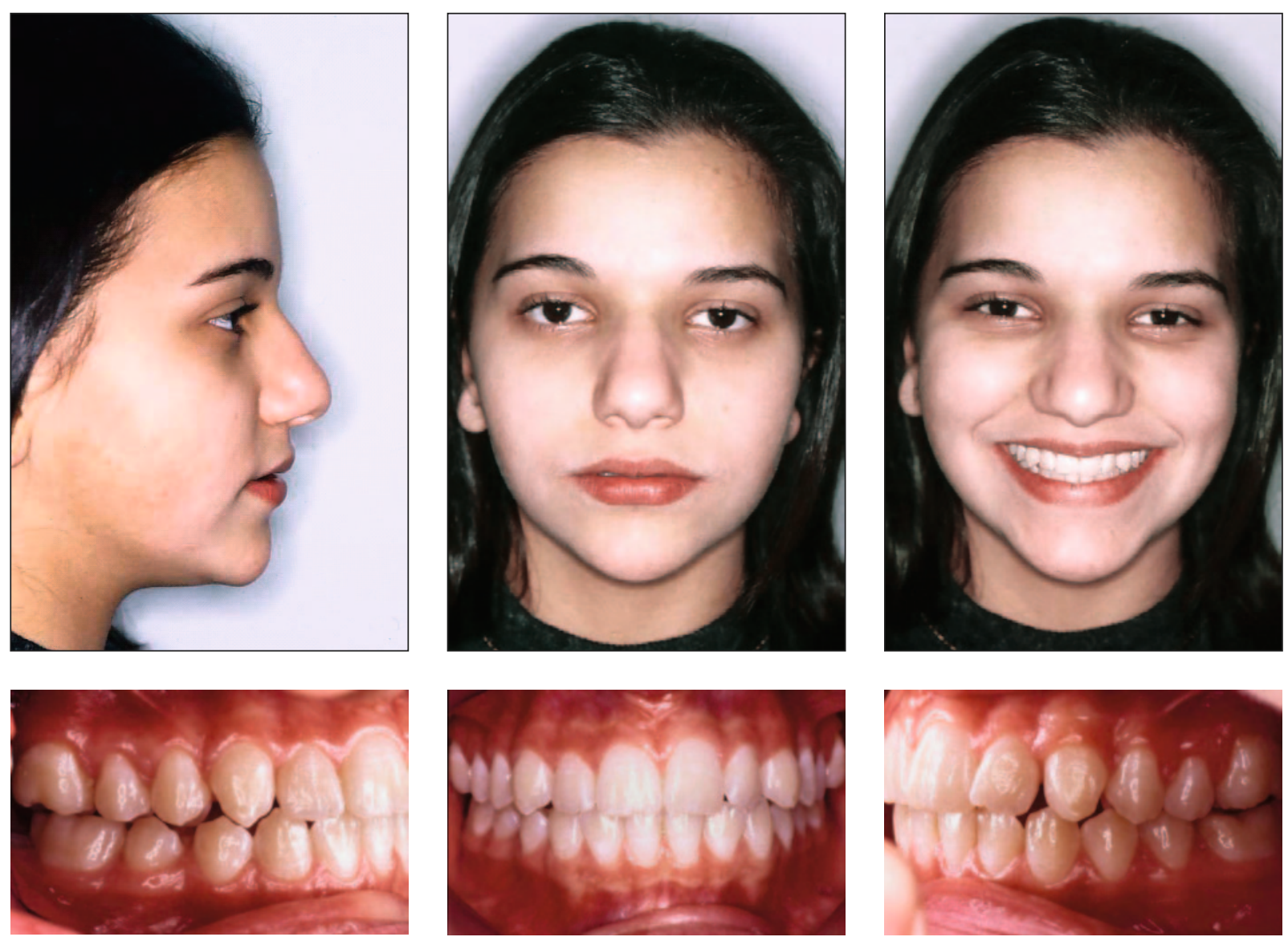

FIGURA 15 - Fotografias faciais e intrabucais intermediárias (A3). 

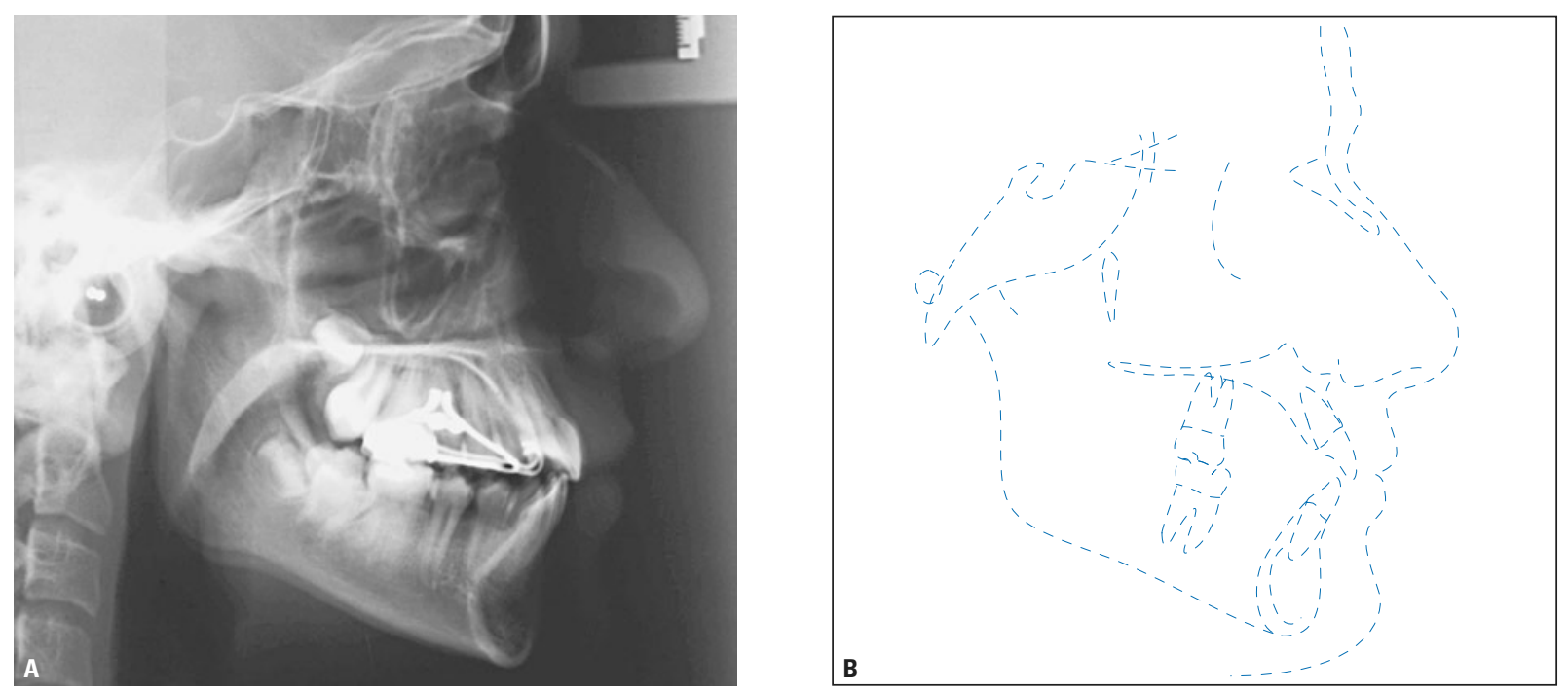

FIGURA 16 - Radiografia cefalométrica de perfil (A) e traçado cefalométrico (B), após a segunda fase do tratamento (A3).
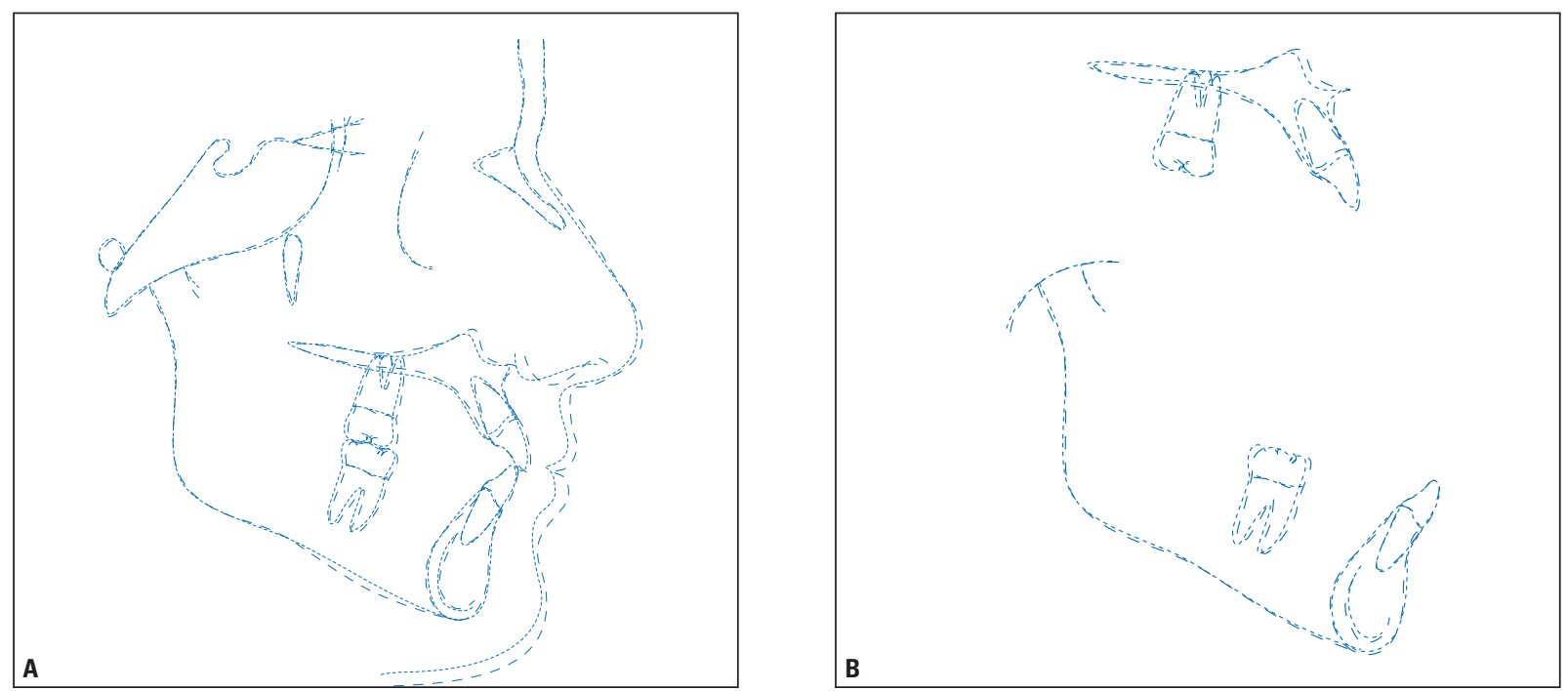

FIGURA 17 - Sobreposições total (A) e parciais (B) dos traçados cefalométricos intermediários A2 (azul tracejado) e A3 (azul com traços espaçados).

intermaxilar com direção de Classe III no lado esquerdo, para estabelecimento de chave de oclusão nos molares.

Vale ressaltar que, assim que possível, os segundos molares inferiores foram incluídos no tratamento. Quanto aos superiores, houve retardo em sua irrupção e, com o intuito de não aumentar ainda mais o tempo de tratamento, desistiu-se de sua inclusão. Nesses casos, adequado monitoramento da irrupção se faz necessário.
Após a finalização do tratamento ortodôntico e a obtenção dos objetivos pretendidos, a aparelhagem ortodôntica fixa foi removida, para a instalação dos aparelhos de contenção. No arco dentário superior, foi utilizada uma placa removível do tipo wraparound e, no arco inferior, uma barra fixa do dente 33 ao 43, com fio de aço inoxidável 0,028”, de secção redonda. Foi recomendada a utilização da placa superior durante 18 horas por dia, no primeiro ano, e, após esse período, uso noturno. 


\section{Resultados obtidos}

Ao final do tratamento, foram solicitados novos exames à paciente (Fig. 18 - 21). Após a avaliação desses, verificou-se que os objetivos foram plenamente alcançados.

O sorriso apresentou-se com boa exposição de incisivos superiores e o lábio inferior paralelo em relação aos dentes superiores. Houve redução da discrepância esquelética anteroposterior em $1^{\circ}$ (ANB passou de $1^{\circ}$ para $2^{\circ}$ ), obtendo-se uma boa relação entre as bases ósseas. O SNA foi aumentado em $7^{\circ}$, terminando em $87^{\circ}$, demonstrando o considerável grau de deslocamento anterior da maxila. O SNB aumentou $6^{\circ}$, atingindo $85^{\circ}$, revelando a grande expressão de crescimento mandibular para frente (Fig. 18 - 22, Tab. 1).
Considerando-se a hipótese de a paciente não ter aceitado o tratamento, ela provavelmente manteria seu SNA inicial de $80^{\circ}$ e seu SNB teria aumentado de $79^{\circ}$ para $85^{\circ}$, gerando um ANB de $-5^{\circ}$. Provavelmente seria um caso a ser tratado com uma combinação ortodôntica-cirúrgica. Isso demonstra a importância do diagnóstico precoce desses pacientes.

$\mathrm{Na}$ avaliação da radiografia panorâmica, observa-se bom posicionamento radicular, com os terceiros molares superiores em formação (Fig. 20).

$\mathrm{Na}$ avaliação dentária, constata-se uma relação de molares e caninos de chave de oclusão, com bom alinhamento dentário, e com trespasses horizontal e vertical dentro dos padrões de normalidade (Fig. 18, 19).
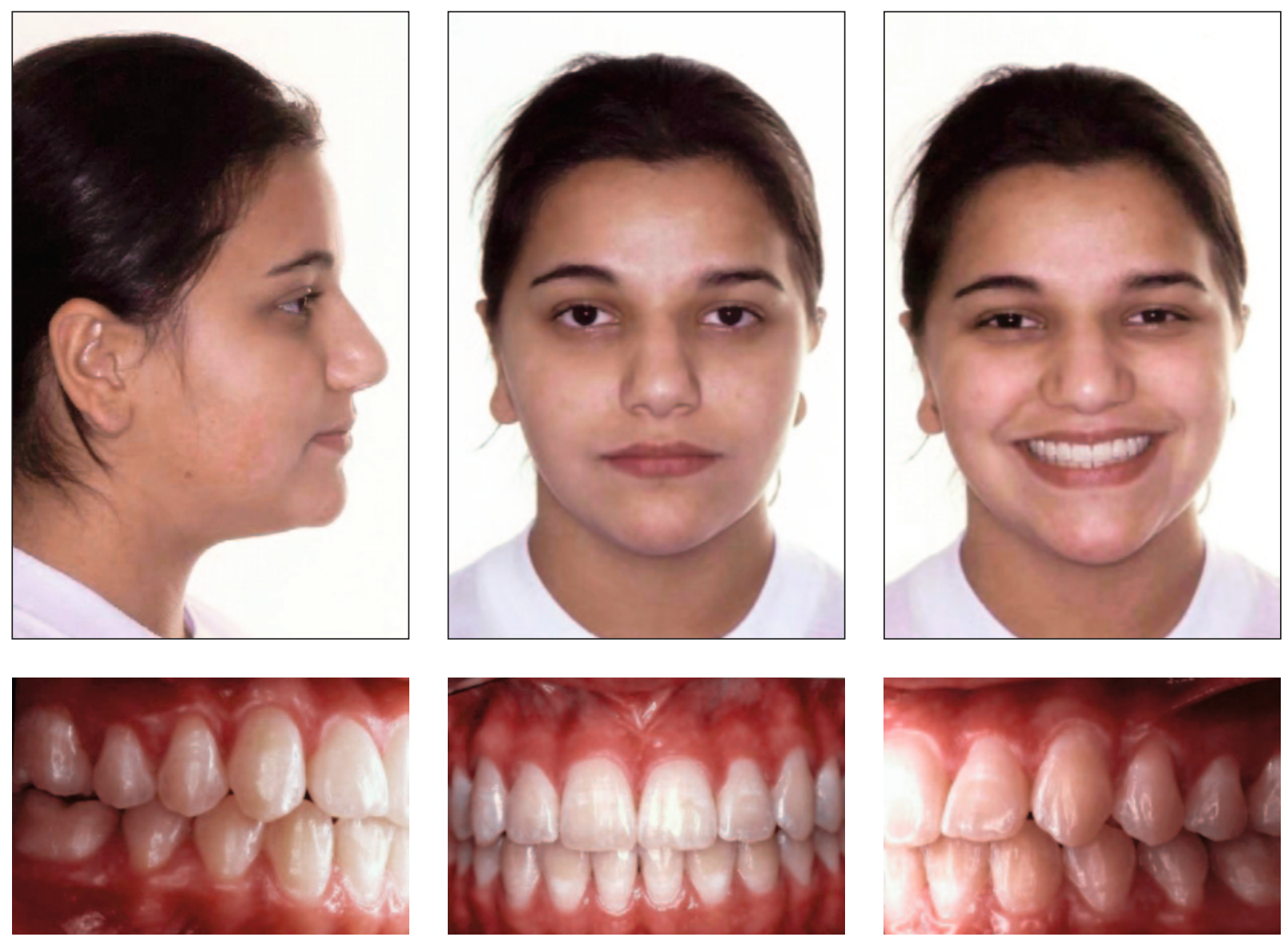

FIGURA 18 - Fotografias faciais e intrabucais finais. 

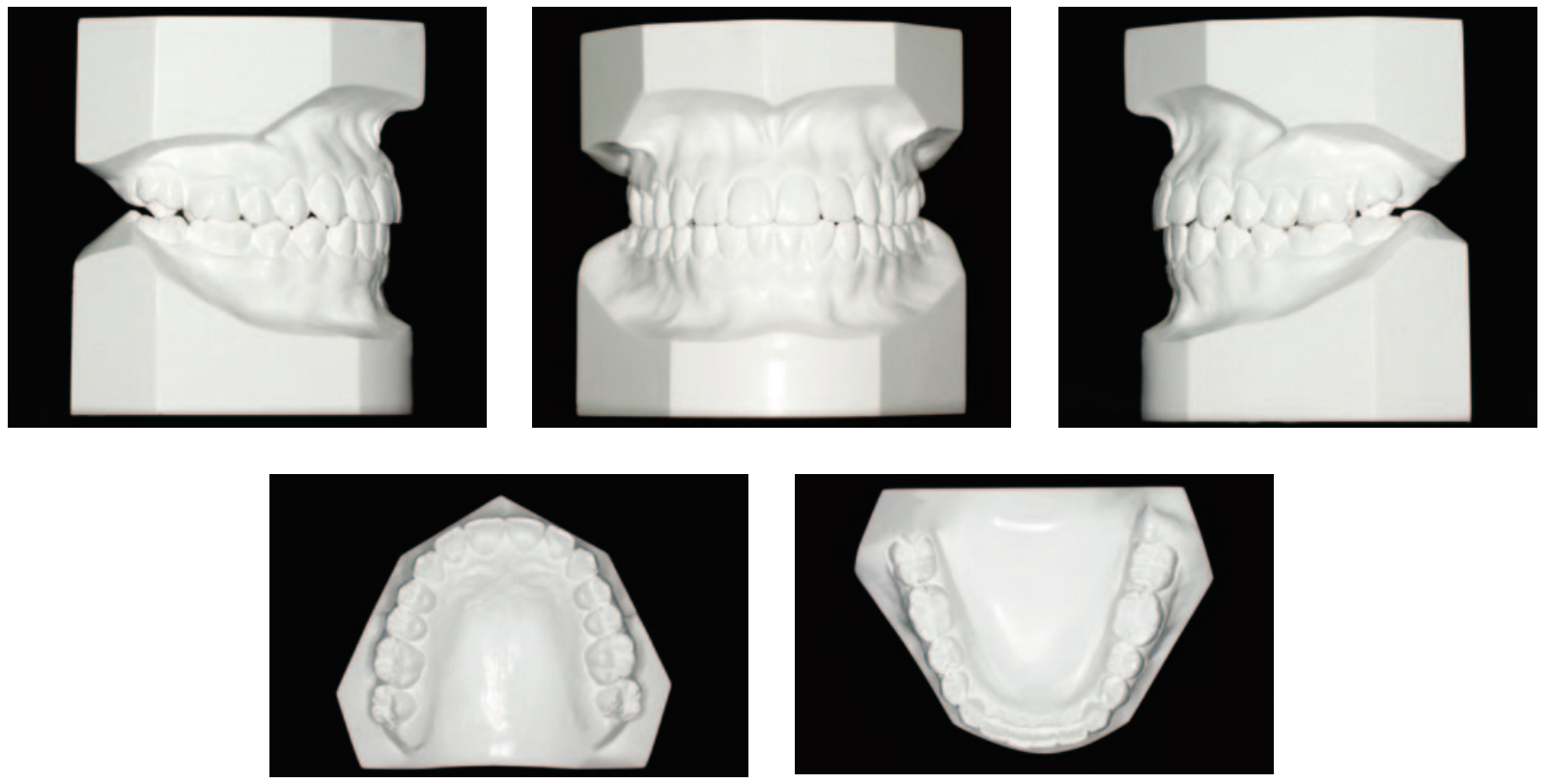

FIGURA 19 - Modelos finais.

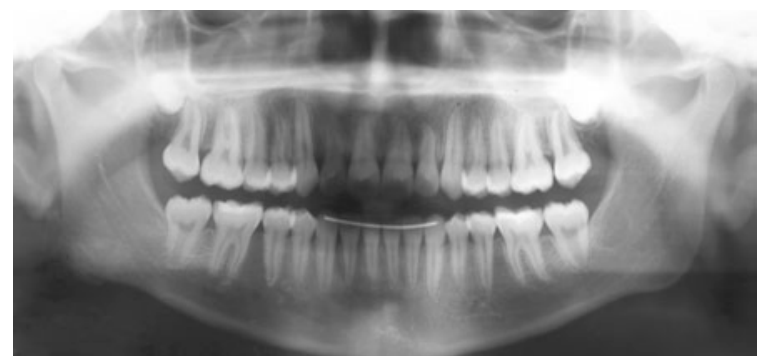

FIGURA 20 - Radiografia panorâmica final.
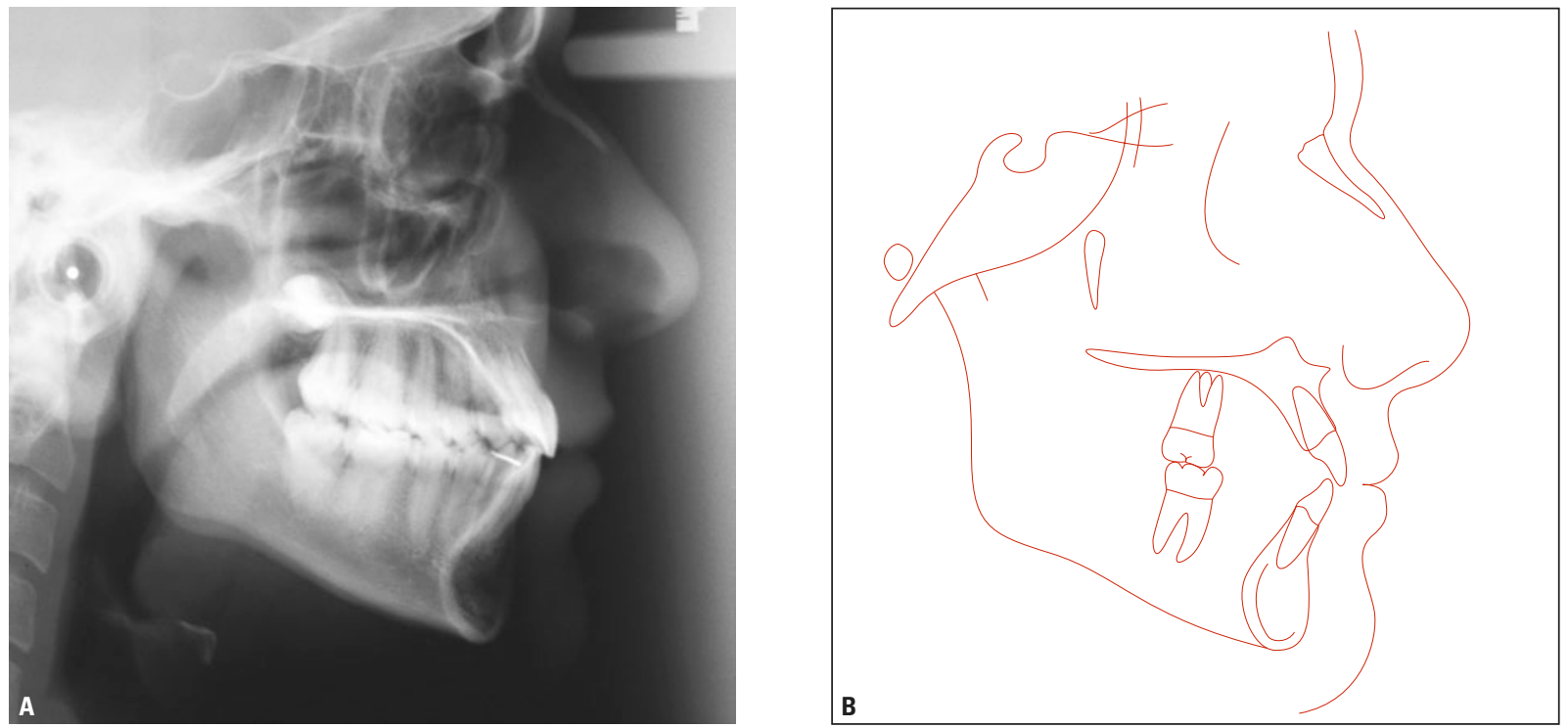

FIGURA 21 - Radiografia cefalométrica de perfil (A) e traçado cefalométrico (B) finais. 

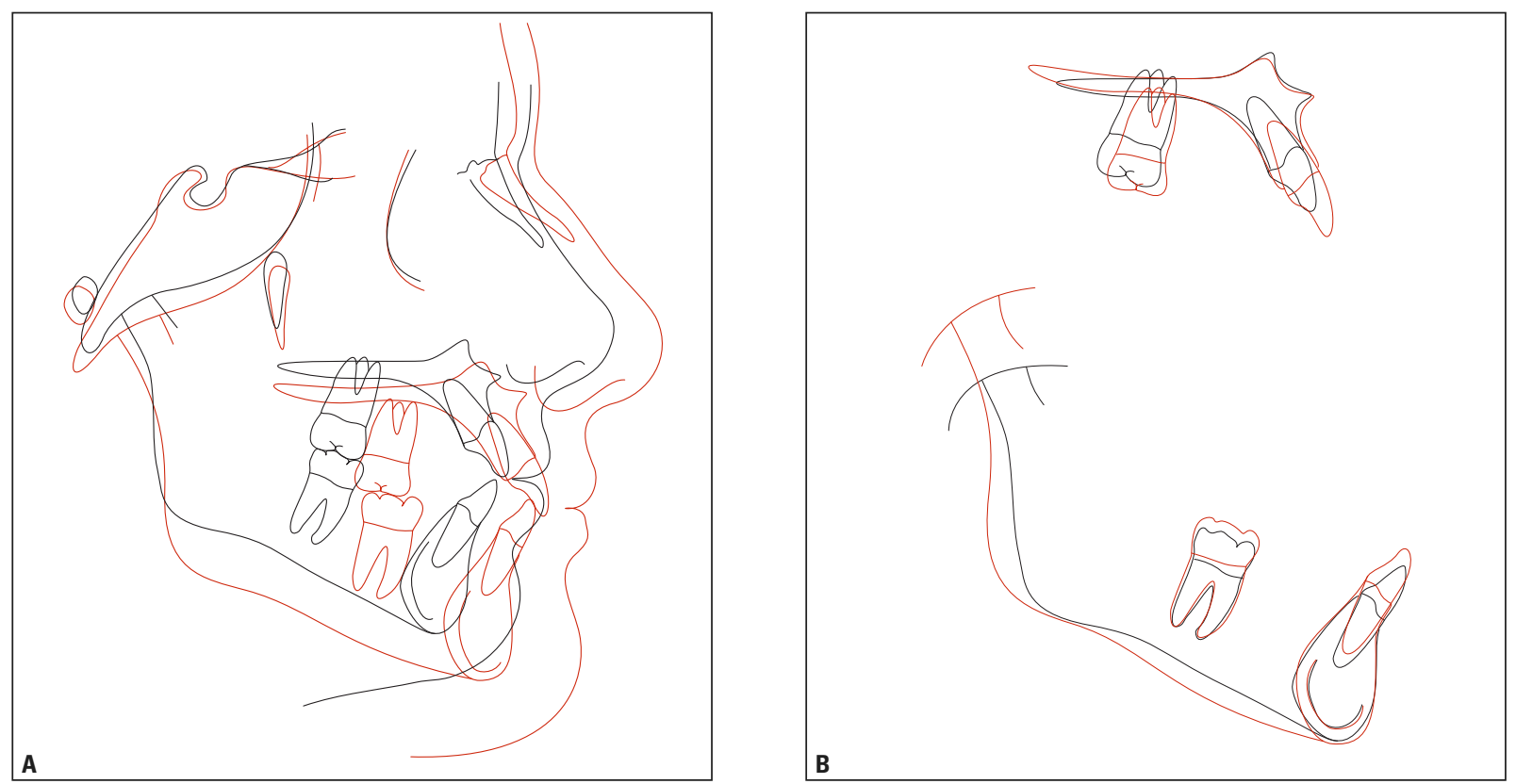

FIGURA 22 - Sobreposições total (A) e parciais (B) dos traçados cefalométricos inicial (preto) e final (vermelho).

TABELA 1 - Resumo das medidas cefalométricas.

\begin{tabular}{|c|c|c|c|c|c|c|c|c|c|}
\hline & MEDIDAS & NORMA & $\mathbf{A}$ & A1 & $A 2$ & $\mathbf{A 3}$ & B & DIFERENÇA A-B & C \\
\hline \multirow{8}{*}{ 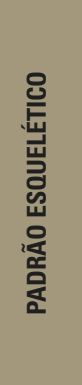 } & SNA (Steiner) & $82^{\circ}$ & $80^{\circ}$ & $85^{\circ}$ & $85^{\circ}$ & $87^{\circ}$ & $87^{\circ}$ & $7^{\circ}$ & $87^{\circ}$ \\
\hline & SNB (Steiner) & $80^{\circ}$ & $79^{\circ}$ & $81^{\circ}$ & $83,5^{\circ}$ & $84^{\circ}$ & $85^{\circ}$ & $6^{\circ}$ & $85^{\circ}$ \\
\hline & ANB (Steiner) & $2^{\circ}$ & $1^{\circ}$ & $4^{\circ}$ & $1,5^{\circ}$ & $3^{\circ}$ & $2^{\circ}$ & $1^{\circ}$ & $2^{\circ}$ \\
\hline & Âng. Conv. (Downs) & $0^{\circ}$ & $2,5^{\circ}$ & $9^{\circ}$ & $4^{\circ}$ & $6^{\circ}$ & $4,5^{\circ}$ & $2^{\circ}$ & $4,5^{\circ}$ \\
\hline & Eixo Y (Downs) & $59^{\circ}$ & $59^{\circ}$ & $59^{\circ}$ & $59^{\circ}$ & $59^{\circ}$ & $59^{\circ}$ & $0^{\circ}$ & $59^{\circ}$ \\
\hline & Âng. Facial (Downs) & $87^{\circ}$ & $87,5^{\circ}$ & $89^{\circ}$ & $90^{\circ}$ & $90^{\circ}$ & $90^{\circ}$ & $2,5^{\circ}$ & $90^{\circ}$ \\
\hline & SN-GoGn (Steiner) & $32^{\circ}$ & $30^{\circ}$ & $30^{\circ}$ & $28^{\circ}$ & $25^{\circ}$ & $25^{\circ}$ & $5^{\circ}$ & $25^{\circ}$ \\
\hline & FMA (Tweed) & $25^{\circ}$ & $23^{\circ}$ & $23^{\circ}$ & $23^{\circ}$ & $23^{\circ}$ & $23^{\circ}$ & $0^{\circ}$ & $23^{\circ}$ \\
\hline \multirow{7}{*}{ 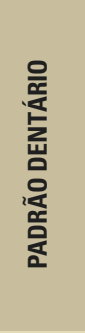 } & IMPA (Tweed) & $90^{\circ}$ & $96^{\circ}$ & $99^{\circ}$ & $98^{\circ}$ & $98^{\circ}$ & $97^{\circ}$ & $1^{\circ}$ & $97^{\circ}$ \\
\hline & 1-NA ${ }^{\circ}$ (Steiner) & $22^{\circ}$ & $25^{\circ}$ & $26^{\circ}$ & $26^{\circ}$ & $27^{\circ}$ & $26^{\circ}$ & $1^{\circ}$ & $26^{\circ}$ \\
\hline & 1-NA mm (Steiner) & $4 \mathrm{~mm}$ & $4 \mathrm{~mm}$ & $3 \mathrm{~mm}$ & $6 \mathrm{~mm}$ & $5 \mathrm{~mm}$ & $5 \mathrm{~mm}$ & $1 \mathrm{~mm}$ & $5 \mathrm{~mm}$ \\
\hline & 1-NB ${ }^{\circ}$ (Steiner) & $25^{\circ}$ & $29^{\circ}$ & $30^{\circ}$ & $30^{\circ}$ & $30^{\circ}$ & $27^{\circ}$ & $2^{\circ}$ & $27^{\circ}$ \\
\hline & 1-NB mm (Steiner) & $4 \mathrm{~mm}$ & $3 \mathrm{~mm}$ & $4 \mathrm{~mm}$ & $5 \mathrm{~mm}$ & $5 \mathrm{~mm}$ & $4 \mathrm{~mm}$ & $1 \mathrm{~mm}$ & $4 \mathrm{~mm}$ \\
\hline & Âng. Interincisal (Downs) & $130^{\circ}$ & $127^{\circ}$ & $115^{\circ}$ & $115^{\circ}$ & $120^{\circ}$ & $125^{\circ}$ & $2^{\circ}$ & $125^{\circ}$ \\
\hline & 1-APo mm (Ricketts) & $1 \mathrm{~mm}$ & $3,5 \mathrm{~mm}$ & $2 \mathrm{~mm}$ & $6 \mathrm{~mm}$ & $3 \mathrm{~mm}$ & $2 \mathrm{~mm}$ & $1,5 \mathrm{~mm}$ & $2 \mathrm{~mm}$ \\
\hline \multirow{2}{*}{ PERFIL } & L.Sup - Linha S (Steiner) & $0 \mathrm{~mm}$ & $2 \mathrm{~mm}$ & $2 \mathrm{~mm}$ & $3 \mathrm{~mm}$ & $5 \mathrm{~mm}$ & $4 \mathrm{~mm}$ & $2 \mathrm{~mm}$ & $4 \mathrm{~mm}$ \\
\hline & L.Inf - Linha S (Steiner) & $0 \mathrm{~mm}$ & $1 \mathrm{~mm}$ & $3 \mathrm{~mm}$ & $1,5 \mathrm{~mm}$ & $2 \mathrm{~mm}$ & $3 \mathrm{~mm}$ & $2 \mathrm{~mm}$ & $3 \mathrm{~mm}$ \\
\hline
\end{tabular}



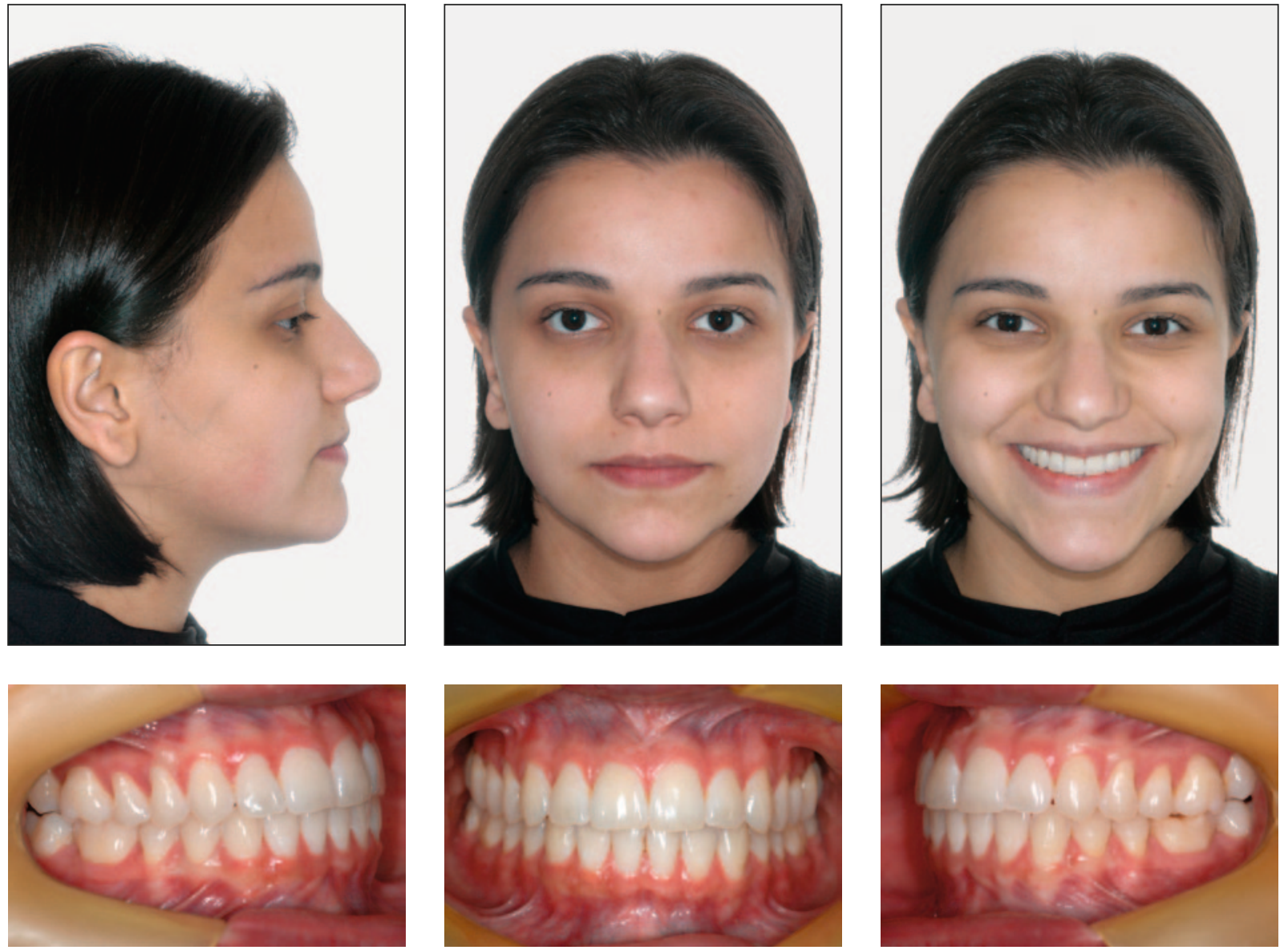

FIGURA 23 - Fotografias faciais e intrabucais pós-contenção.
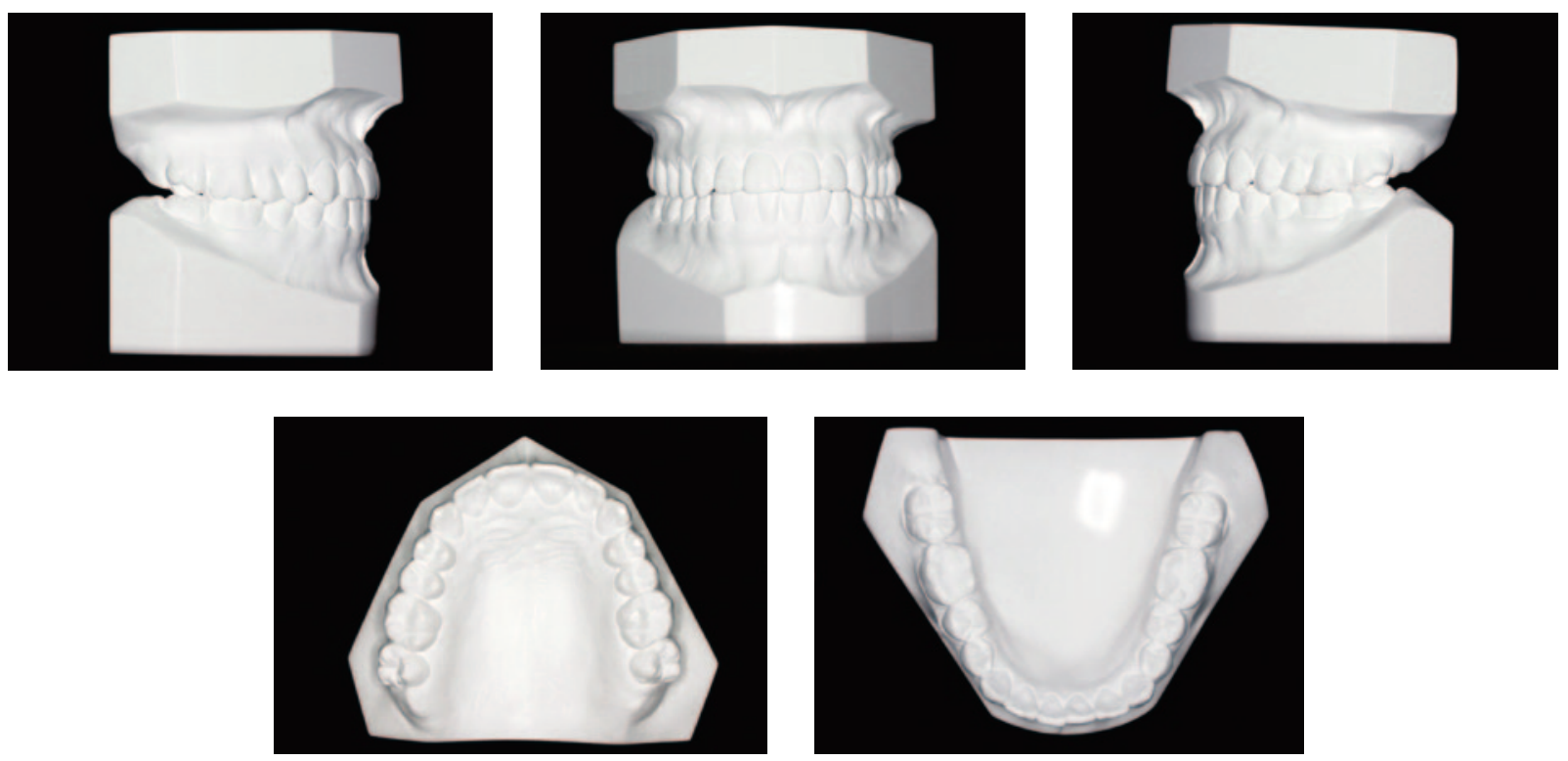

FIGURA 24 - Modelos pós-contenção. 


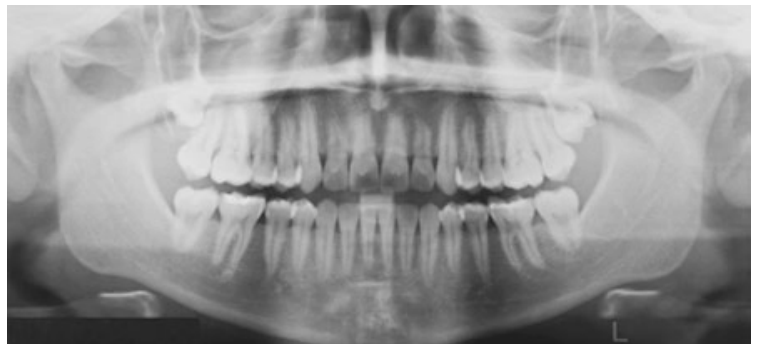

FIGURA 25 - Radiografia panorâmica pós-contenção.
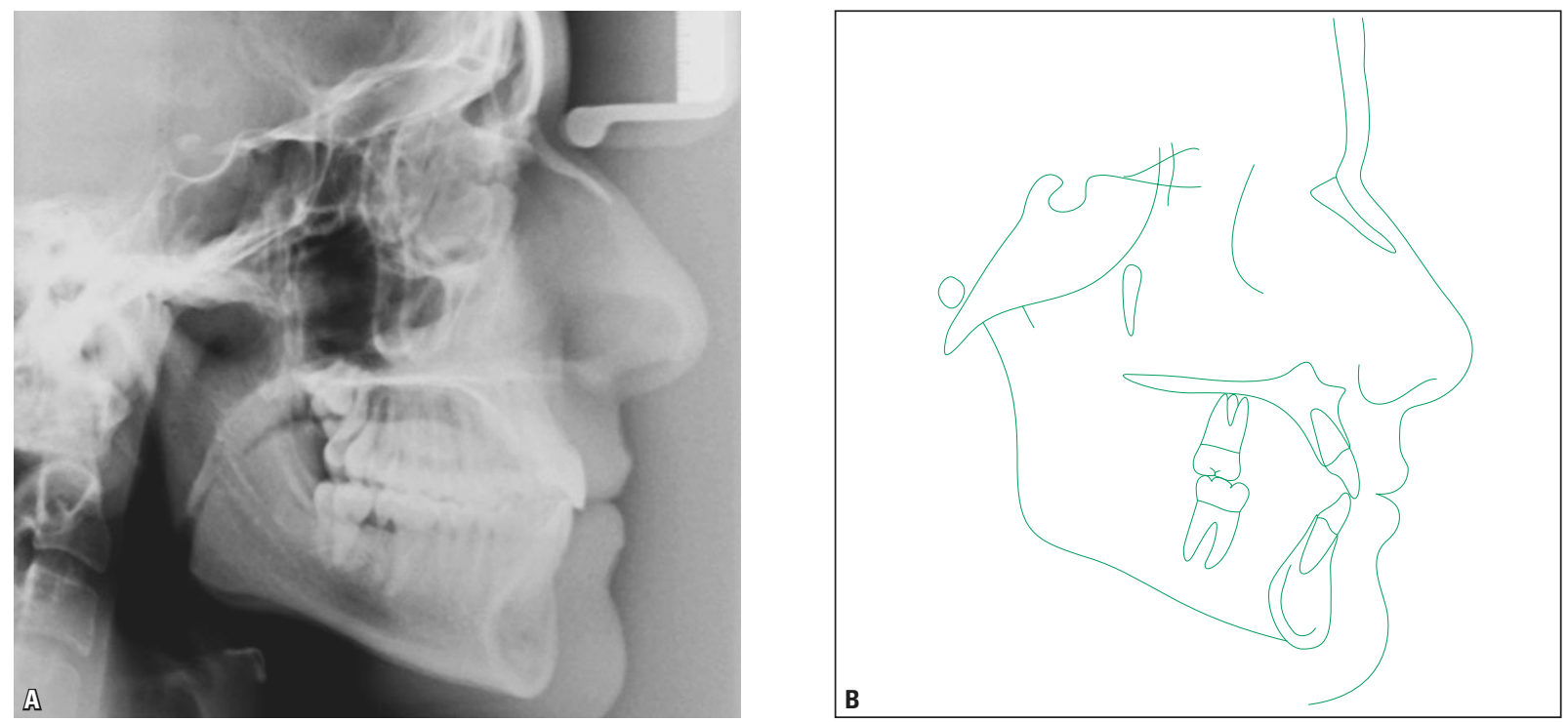

FIGURA 26 - Radiografia cefalométrica de perfil (A) e traçado cefalométrico (B) pós-contenção.
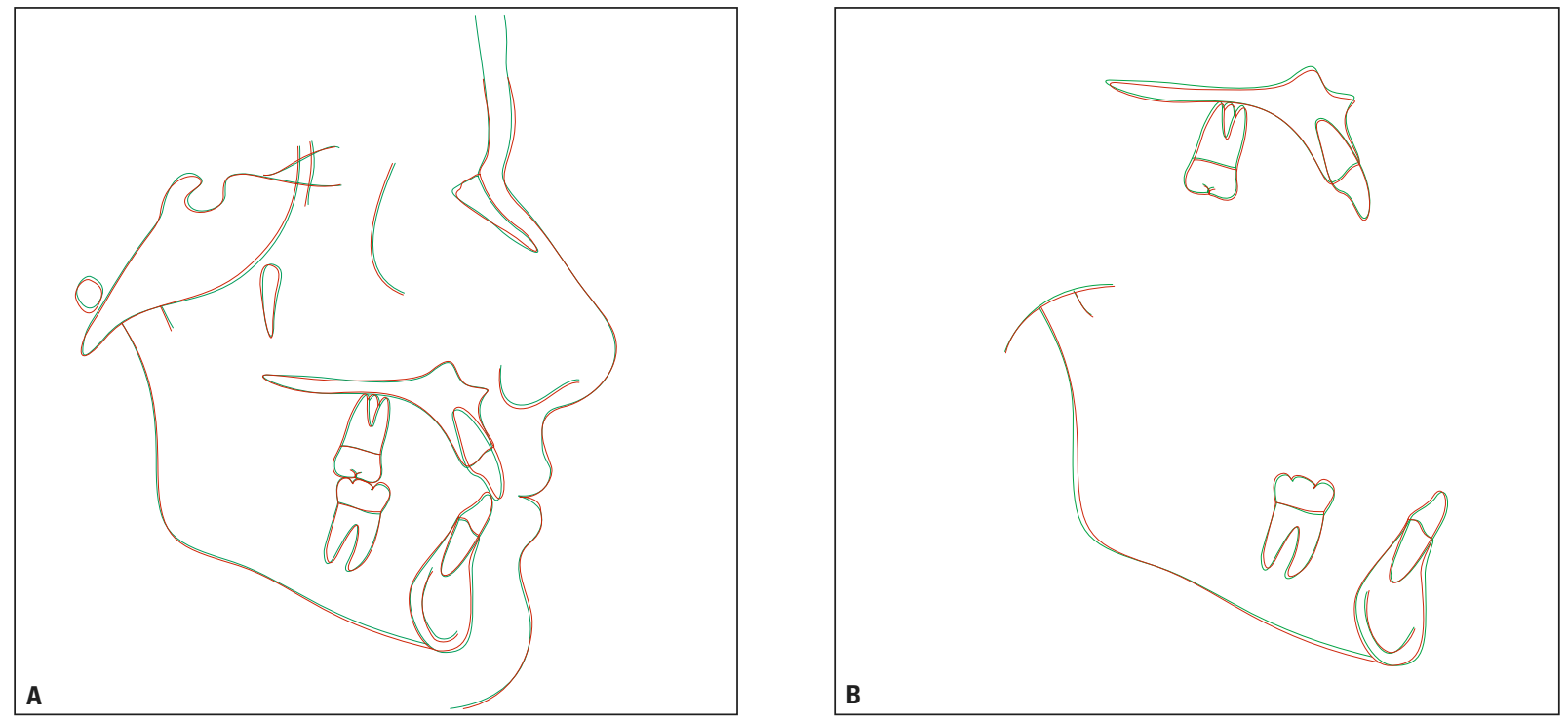

FIGURA 27 - Sobreposições total (A) e parciais (B) dos traçados cefalométricos final (vermelho) e pós-contenção (verde). 


\section{CONSIDERAÇÕES FINAIS}

A má oclusão de Classe III de Angle possui um caráter etiológico multifatorial, o que dificulta a previsão do padrão de crescimento dos diversos elementos do complexo craniofacial. Ela pode ser composta por um componente dentário (devido à perda precoce de segundos molares decíduos inferiores, por exemplo) e/ou um componente esquelético (mecanismos genéticos ou epigenéticos de controle do crescimento). Esse último pode estar relacionado à deficiência de desenvolvimento no terço médio da face, ao crescimento mandibular excessivo ou a uma combinação de ambos ${ }^{14}$.

O plano de tratamento varia muito de acordo com a idade em que o paciente for abordado. Em pacientes com potencial de crescimento, a terapia com máscara facial, associada à disjunção palatina, tem se mostrado uma grande aliada do ortodontis$\mathrm{ta}^{13}$. Já em pacientes sem potencial de crescimento, resta a opção de camuflagem, em casos não muito severos; ou a correção combinada ortodôntico-cirúrgica, em casos com maior discrepância.

Anteriormente ao advento da máscara facial, o tratamento de pacientes com potencial de crescimento era realizado, normalmente, de três formas. Podia envolver o uso de mentoneiras, para restringir o crescimento mandibular ${ }^{8}$; o avanço dos dentes anterossuperiores, com retração dos anteroinferiores; ou, simplesmente, o monitoramento até a idade ideal para a realização da cirurgia ortognática.

A literatura é controversa em relação ao ganho anteroposterior com o uso da máscara facial. Segundo alguns autores, quando o mesmo é observado, é considerado insignificante. Outros estudos afirmam haver significativo avanço maxilar ${ }^{2,5,6,7,11}$. Porém, em 2002, Turley ${ }^{12}$ constatou uma média de avanço maxilar, com essa terapia, de $3,3 \mathrm{~mm}$ (sendo que 6 entre 21 pacientes apresentaram ganho de $5 \mathrm{~mm}$ a $8 \mathrm{~mm}$ ) e aumento médio do ângulo SNA de $2,35^{\circ}$ ( 5 entre 21 pacientes apresentaram aumento de $4^{\circ}$ a $5^{\circ}$ ), resultados certamente significativos. $\mathrm{O}$ autor credita essa disparidade de resultados à diferença no protocolo de tratamento utilizado pelos diferentes autores, incluindo o desenho do aparelho, as horas usadas por dia e o tempo total de tratamento. Portanto, a combinação da máscara facial com a expansão palatina se mostrou um método efetivo de tratamento para o caso relatado, o qual possuía um prognóstico duvidoso, em função da dificuldade de controle do crescimento mandibular.

As modificações faciais decorrentes da terapia são uma combinação de movimentos dentários e esqueléticos, nos sentidos vertical e anteroposterior ${ }^{10}$. Além do movimento maxilar para baixo e para frente, a mandíbula sofre uma rotação horária e os dentes anterossuperiores também se movimentam.

Outro aspecto muito importante a ser considerado é a época em que o tratamento é iniciado. Indivíduos mais jovens tendem a apresentar resultados mais favoráveis, sendo que as melhores idades estão na faixa entre 4 e 10 anos, embora os pacientes entre 10 e 14 anos ainda apresentem resultados positivos ${ }^{1}$. Acredita-se que o resultado obtido é decorrente do fato de a paciente ter se apresentado no estágio inicial da dentadura mista, com bom potencial de crescimento.

Como é possível perceber por meio desse caso, a sobrecorreção é indicada, pois o paciente continua apresentando um padrão desfavorável de crescimento $^{12}$. Mesmo com essa sobrecorreção, alguns pacientes ainda necessitam de uma segunda fase de tratamento com a máscara facial. A estabilidade do tratamento a curto prazo é boa, porém, a longo prazo ainda são necessários mais estudos. Apresentamos, aqui, uma documentação de controle após seis anos do término do tratamento, mostrando a estabilidade alcançada (Fig. 23 - 27). Vale ressaltar que o aparelho de contenção superior foi suspenso e a barra intercaninos removida quando a paciente completou 21 anos de idade. Portanto, os exames apresentados são referentes a um período de 30 meses pós-contenção.

A característica mais frequente em um paciente que apresenta uma má oclusão de Classe III em 
desenvolvimento é a deficiência anteroposterior e vertical da maxila, associada a uma mandíbula normal ou levemente protruída e, ainda, a uma sobremordida normal ou exagerada ${ }^{3,4,9}$. Essa informação nos remete à importância e à vasta aplicabilidade da terapia com máscara facial, considerando o grande número de pacientes com deficiência de terço médio que, com ela, podem ser beneficiados.

\title{
Angle Class I malocclusion, with class III skeletal tendency, treated with growth control
}

\begin{abstract}
Angle Class III malocclusion is characterized by an anteroposterior dental alteration, which might be accompanied by skeletal deformities. Usually, the facial aspect becomes aesthetically compromised, mostly when the middle third of the face is affected (this is the main reason why patients seek for treatment). This case was presented to the directorship of the Brazilian Board of Orthodontics and Facial Orthopedics (BBO), standing for the free category, as a part of the requirements to obtain the Board's Certificate.
\end{abstract}

Keywords: Malocclusion, Angle Class III. Maxillary traction. Maxillary disjunction.

\section{REFERÊNCIAS}

1. BACCETTI, T.; McGILL, J. S.; FRANCHI, L.; MCNAMARA, J. A.; TOLLARO, I. Skeletal effects of early treatment of Class III malocclusion with maxillary expansion and face-mask therapy. Am. J. Orthod. Dentofacial Orthop., St. Louis, v. 113, no. 3, p. 333-343, Mar. 1998.

2. BAIK, H. S. Clinical results of the maxillary protraction in Korean children. Am. J. Orthod. Dentofacial Orthop., St. Louis, v. 108, no. 6, p. 583-592, Dec. 1995

3. HOPKIN, G. B. Craniofacial pattern in mesioocclusion. Am. J. Orthod. Dentofacial Orthop., St. Louis, v. 52, no. 12, p. 927-928, Dec. 1966.

4. HOPKIN, G. B.; HOUSTON, W. J. B.; JAMES, G. A. The cranial base as an etiological factor in malocclusion. Angle Orthod., Appleton, v. 38, no. 3, p. 250-255, July 1968.

5. KAPUST, A. J.; SINCLAIR, P. M.; TURLEY, P. K. Cephalometric effects of face mask/expansion therapy in Class III children: A comparison of three age groups. Am. J. Orthod. Dentofacial Orthop., St. Louis, v. 113, no. 2, p. 204-212, Feb. 1998.

6. MAcDONALD, K. E.; KAPUST, A. J.; TURLEY, P. K. Cephalometric changes after the correction of Class III malocclusion with maxillary expansion/facemask therapy. Am. J. Orthod. Dentofacial Orthop., St. Louis, v. 116, no. 1, p. 13-24, July 1999.

7. MERMIGOS, J.; FULL, C. A.; ANDREASEN, G. Protraction of the maxillofacial complex. Am. J. Orthod. Dentofacial Orthop., St. Louis, v. 98, no. 1, p. 47-55, July 1990.

8. MITANI, H. Entrevista. R. Dental Press Ortodon. Ortop. Facial, Maringá, v. 14, n. 3, p. 25-33, maio/jun. 2009.

9. MOUKAEH, M. Cephalometric evaluation of craniofacial pattern of Syrian children with Class III malocclusion. Am. J. Orthod. Dentofacial Orthop., St. Louis, v. 119, no. 6, p. 640-649, June 2001.
10. NARTALLO-TURLEY, P. E.; TURLEY, P. K. Cephalometric effects of combined palatal expansion and facemask therapy on Class III malocclusion. Angle Orthod., Appleton, v. 68, no. 3, p. 217-224, June 1998.

11. SUNG, S. J.; BAIK, H. S. Assessment of skeletal and dental changes by maxillary protraction. Am. J. Orthod. Dentofacial Orthop., St. Louis, v. 114, no. 5, p. 492-502, Nov. 1998.

12. TURLEY, P. K. Managing the developing Class III malocclusion with palatal expansion and facemask therapy. Am. J. Orthod. Dentofacial Orthop., St. Louis, v. 122, no. 4, p. 349-352, Oct. 2002

13. TURLEY, P. K. Orthopedic correction of Class III malocclusion with palatal expansion and custom protraction headgear. J. Clin. Orthod., Boulder, v. 22, no. 5, p. 314-325, May 1988.

14. WEISSHEIMER, F.; BRUNETTO, A. R.; PETRELLI, E. Disjunção palatal e protração maxilar: alterações cefalométricas póstratamento. JBO: J. Bras. Ortodon. Ortop. Facial, Curitiba, v. 8, n. 44, p. 111-121, mar./abr. 2003.

Endereço para correspondência

Ademir Roberto Brunetto

Av. 7 de Setembro, 4456

CEP: 80.250-210 - Curitiba/PR

E-mail: ortobrunetto@terra.com.br 